\title{
A mathematical model of compartmentalized neurotransmitter metabolism in the human brain
}

\author{
ROLF GRUETTER, ${ }^{1}$ ELIZABETH R. SEAQUIST, ${ }^{2}$ AND KÂMIL UGURBIL ${ }^{1,2,3}$ \\ Departments of ${ }^{1}$ Radiology, ${ }^{2}$ Medicine, and ${ }^{3}$ Biochemistry, Center for Magnetic Resonance Research \\ and General Clinical Research Center, University of Minnesota, Minneapolis, Minnesota 55455
}

Received 7 June 2000; accepted in final form 22 February 2001

\begin{abstract}
Gruetter, Rolf, Elizabeth R. Seaquist, and Kâmil Ugurbil. A mathematical model of compartmentalized neurotransmitter metabolism in the human brain. Am $J$ Physiol Endocrinol Metab 281: E100-E112, 2001.-After administration of enriched $\left[1-{ }^{13} \mathrm{C}\right]$ glucose, the rate of ${ }^{13} \mathrm{C}$ label incorporation into glutamate $\mathrm{C} 4, \mathrm{C} 3$, and $\mathrm{C} 2$, glutamine $\mathrm{C} 4, \mathrm{C} 3$, and $\mathrm{C} 2$, and aspartate $\mathrm{C} 2$ and $\mathrm{C} 3$ was simultaneously measured in six normal subjects by ${ }^{13} \mathrm{C}$ NMR at 4 Tesla in $45-\mathrm{ml}$ volumes encompassing the visual cortex. The resulting eight time courses were simultaneously fitted to a mathematical model. The rate of (neuronal) tricarboxylic acid cycle flux $\left(V_{\mathrm{PDH}}\right), 0.57 \pm 0.06 \mu \mathrm{mol} \cdot \mathrm{g}^{-1} \cdot \mathrm{min}^{-1}$, was comparable to the exchange rate between (mitochondrial) 2-oxoglutarate and (cytosolic) glutamate $\left(V_{\mathrm{x}}, 0.57 \pm 0.19 \mu \mathrm{mol} \cdot \mathrm{g}^{-1} \cdot \mathrm{min}^{-1}\right)$, which may reflect to a large extent malate-aspartate shuttle activity. At rest, oxidative glucose consumption $\left[\mathrm{CMR}_{\mathrm{Glc}(\mathrm{ox})}\right]$ was $0.41 \pm 0.03 \mu \mathrm{mol} \cdot \mathrm{g}^{-1} \cdot \mathrm{min}^{-1}$, and (glial) pyruvate carboxylation $\left(V_{\mathrm{PC}}\right)$ was $0.09 \pm 0.02 \mu \mathrm{mol} \cdot \mathrm{g}^{-1} \cdot \mathrm{min}^{-1}$. The flux through glutamine synthetase $\left(V_{\text {syn }}\right)$ was $0.26 \pm 0.06$ $\mu \mathrm{mol} \cdot \mathrm{g}^{-1} \cdot \mathrm{min}^{-1}$. A fraction of $V_{\text {syn }}$ was attributed to be from (neuronal) glutamate, and the corresponding rate of apparent glutamatergic neurotransmission $\left(V_{\mathrm{NT}}\right)$ was $0.17 \pm 0.05$ $\mu \mathrm{mol} \cdot \mathrm{g}^{-1} \cdot \mathrm{min}^{-1}$. The ratio $\left[V_{\mathrm{NT}} / \mathrm{CMR}_{\mathrm{Glc}(\mathrm{ox})}\right]$ was $0.41 \pm 0.14$ and thus clearly different from a 1:1 stoichiometry, consistent with a significant fraction $(\sim 90 \%)$ of ATP generated in astrocytes being oxidative. The study underlines the importance of assumptions made in modeling ${ }^{13} \mathrm{C}$ labeling data in brain.
\end{abstract}

nuclear magnetic resonance; glutamate; neurotransmission; in vivo spectroscopy

IN THE TRADITIONAL CONTEXT of neuroscience, the brain's tasks are mainly accomplished by the neurons, with the surrounding glial cells performing simple, passive tasks of maintaining the milieu required for optimal neurotransmission. However, the glial cells are more than just passive components in neuronal function, in that they are intimately involved in the process of neurotransmission through glial uptake of glutamate (Glu) from the synaptic cleft $(64,77,78)$. Glu is the major excitatory neurotransmitter (62); it is present in the mammalian brain in high concentrations and is dynamically stored in presynaptic vesicles (73). Despite the high intracellular concentration of Glu, the

\footnotetext{
Address for reprint requests and other correspondence: R. Gruetter, Center for MR Research and General Clinical Research Center, 2021 6th St. SE, Minneapolis, MN 55455 (E-mail: gruetter@cmrr. umn.edu).
}

extracellular concentration must be maintained very low $(\sim 0.004 \mathrm{mM})$ to avoid excitotoxicity. Presynaptic release of Glu into the synaptic cleft therefore requires efficient uptake mechanisms, which are achieved by Glu transporters (2). Most of the metabolic evidence suggests that uptake by glia is the most important process. Most of the Glu is in neurons (51), as is most of the glutaminase activity (52), whereas astrocytes contain most of the glutamine (Gln) (51), all of the glutamine synthetase (42), and pyruvate carboxylase (63); they predominantly take up and metabolize acetate (74). Early studies showed that cerebral Glu metabolism is compartmentalized, involving two major metabolic pools of Glu (7, 16, 71). The large pool has been associated with the neuronal compartment and the small pool with the glial compartment. Recent studies have again supported the participation of glia in neurotransmission through rapid clearance of Glu from the synaptic cleft into neighboring glia, on the basis of conductance currents associated with Glu uptake (6) and consequent metabolism. The uptake of Glu into the astrocytes is associated with uptake of glucose into the glial compartment (39), thereby linking stimulated energy metabolism between glial and neuronal cells during neurotransmission.

In summary, the glial-neuronal metabolic relationship mediated by Glu-Gln interconversion appears to be essential for glutamatergic neurotransmission. This compartmentation of metabolic pathways into both the glial and neuronal fractions extends to other systems as well and may represent a fundamentally important biochemical process for cerebral tissue. For instance, aspartate-like immunoreactivity was recently found to colocalize with Glu in brain slices (25), and aspartate aminotransferase stained the neuronal compartment most intensely (75).

In recent years, ${ }^{13} \mathrm{C} \mathrm{NMR}$ spectroscopy of brain slices (4), extracts $(37,64)$, and cell cultures $(9,26,46)$ has corroborated and extended the initial findings of compartmentalized cerebral energy and Glu metabolism. Given the specific compartmentation of critical enzymes for cerebral energy metabolism, the use of ${ }^{13} \mathrm{C}$ NMR spectroscopy offers an unprecedented amount of

\footnotetext{
The costs of publication of this article were defrayed in part by the payment of page charges. The article must therefore be hereby marked "advertisement" in accordance with 18 U.S.C. Section 1734 solely to indicate this fact.
} 
highly specific information (17). Such data are obtained from the amount of label incorporated into the different positions of one or more molecules after administration of a specifically labeled metabolic precursor, such as glucose, the major source of energy in brain (3, $5,57,68)$. From the specific labeling pattern, the relative and absolute fluxes through a given pathway can be calculated. For example, the incorporation of multiply labeled glucose into multiply labeled Glu at the C2 position is indicative of pyruvate carboxylase flux at low enrichment (37). The specific information gained by ${ }^{13} \mathrm{C}$ NMR spectroscopy can also be used to estimate rates of pyruvate recycling and of malic enzyme activity $(17,47)$. In addition to the analysis of isotopomers $(33,40)$, which has been in widespread use for analyzing ${ }^{13} \mathrm{C}$ NMR spectra of brain extracts (68), dynamic incorporation of label into a given position can be observed. Metabolic rates can be quantitatively extracted from the rate of label incorporation. These approaches require by necessity that accurate temporal data be obtained in vivo, but the derivation of metabolic rates depends more critically on the specific model used to analyze the data and the assumptions made (76). In brain, several models have been proposed, some of which have been used to calculate metabolic rates $(17,23,44,67,72)$. Given the compartmentation of cerebral enzymes, such as glutamine synthetase, the landmark observation that Gln labeling can be detected noninvasively in the brain $(19,21$, 23 ) is thus of crucial importance to the study of metabolic compartmentation, as pointed out in a recent review (3).

The aim of this study was to fully incorporate the maximum information achievable in in vivo localized ${ }^{13} \mathrm{C}$ NMR spectra of human brain using state-of-the-art sensitivity and methodology (20) available at 4 Tesla. The resulting measurement of label incorporation into eight distinct resonances in amino acids was predicted to provide metabolic rates that are less dependent on each other. Overall, on the basis of known cellular compartmentation of metabolism and enzymes, we sought to determine whether sufficiently specific information could be obtained from the human brain to permit assessment of cellular cerebral energy metabolism in vivo. This information can then be used further to serve as a basis for unraveling the relative contributions of both cell types to brain function in health and disease.

\section{MATERIALS AND METHODS}

Subjects. Six healthy human subjects were studied after giving informed consent according to procedures approved by the Institutional Review Board: Human Subjects Committee. On the morning of study, subjects reported to the Center for Magnetic Resonance Research (University of Minnesota) in the fasting state. In preparation for the clamp procedure, an intravenous catheter was placed antegrade in each forearm and retrograde in a lower leg/foot. Arms and legs were warmed by placing preheated pads and water-soaked towels around the lower extremities. Somatostatin was infused into one arm vein at a progressively increasing rate up to 0.16 $\mu \mathrm{g} \cdot \mathrm{kg}^{-1} \cdot \mathrm{min}^{-1}$ to suppress endogenous pancreatic insulin and glucagon secretion (61). Dextrose (50\% wt/vol D-glucose) was infused into the other arm vein at a variable rate adjusted to maintain target glycemia at $15 \mathrm{mM}$ plasma glucose concentration. The infusion procedures have been described previously (23). Alterations in the glucose infusion rate were made on the basis of plasma glucose concentration measured on a nearby glucose analyzer (Beckman, Fullerton, CA) in blood samples taken from the foot vein every $3-5 \min (60)$. Additional blood samples were obtained every $20 \mathrm{~min}$ for the later determination of plasma insulin concentration, and both before and after the study for assessment of plasma ketone levels. When the subject was ready for spectroscopic study, a bolus injection of $30 \mathrm{~g}$ of $\left[1^{13} \mathrm{C}\right]$ glucose was given as $50 \%$ D-glucose in water, with a fractional enrichment of $99 \%$ over 1-2 min. As in our previous study (23), the plasma glucose was then clamped at the peak level of glycemia $(\sim 15$ $\mathrm{mM}$ plasma glucose concentration) by the infusion of $10 \mathrm{~g}$ $\left[1{ }^{13}\right.$ C]glucose (prepared as $20 \%$ D-glucose in water with a fractional enrichment of $70 \%$ ) at a variable rate determined by the plasma glucose concentrations. After administration of $\left[1-{ }^{13} \mathrm{C}\right]$ glucose, additional plasma samples were collected every $10 \mathrm{~min}$ to be used for the determination of plasma glucose enrichment by use of gas chromatography-mass spectrometry (GC-MS).

Chemical assays and GC-MS. Insulin was measured in serum that had been frozen within 30 min of acquisition with the double-antibody method of Morgan and Lazarow (50). Plasma insulin was not detected in our study. Absence of serum ketones was verified in the clinical laboratory by a qualitative test based on the nitroferrocyanide reaction.

Analyses of the ${ }^{13} \mathrm{C}$ enrichment in serum glucose were performed by the University of Minnesota General Clinical Research Center GC/MS Core Laboratory by use of the following standard procedures. After deproteinization, the supernatants were purified by chromatography, as previously described (8). The fraction containing glucose was converted to the pentatrimethylsilyl $O$-methyloxime derivative by a modification of the procedure of Laine and Sweeley (35). After the trimethylsilyl derivative was produced, analysis by GC-MS was performed on a Hewlett-Packard 5973 MSD system equipped with an HP6890 series gas chromatograph in the selective ion-monitoring mode. Ions at 160 and 161 were analyzed to determine the enrichment of ${ }^{13} \mathrm{C}$ in carbon 1 of glucose.

${ }^{13} \mathrm{C} M R$ spectroscopy. All studies used a 4-Tesla magnet with a $125-\mathrm{cm}$ bore, equipped with a standard clinical body gradient coil and amplifier (Siemens AS25, Erlangen, Germany). The magnet and gradient system was interfaced with a spectrometer console (Varian, Palo Alto, CA) by use of a manufacturer-supplied interface board. Subjects were positioned supine on the patient bed above the surface coil. After coil tuning, MR imaging was performed to determine localization for spectroscopy according to anatomical landmarks. Subjects wore earplugs to minimize gradient noise and were placed into the coil holder with cushions to minimize head movement. Shimming of the identified region of interest was performed using FASTMAP (19), which resulted in water linewidths of 7-9 $\mathrm{Hz}$.

To efficiently separate the proton $(169 \mathrm{MHz})$ and the ${ }^{13} \mathrm{C}$ frequency (42.5 MHz), we used a three-coil design in which the circular polarized ${ }^{1} \mathrm{H}$ radio frequency $(\mathrm{RF})$ field was generated by two distinct 14-cm-diameter coils driven by a quadrature hybrid. The ${ }^{13} \mathrm{C}$ coil was a single-loop 9-cmdiameter surface coil. This three-coil design was recently described elsewhere (1). Observation of the Federal Drug Administration guidelines for power absorption was verified using methods and procedures presented in detail elsewhere 
$(1,20,23) . R F$ power for excitation, polarization transfer, and decoupling was carefully calibrated using a small sphere containing $0.5 \mathrm{ml}$ of ${ }^{13} \mathrm{C}$-labeled formic acid placed at the ${ }^{13} \mathrm{C}$ coil center, as described previously (for example, see Ref. 20). These calibrations were used to ensure proper power settings for decoupling as well as to minimize RF power needed for the experiment.

Localization was performed on the longitudinal proton $z$-magnetization, which was transferred to the ${ }^{13} \mathrm{C}$ magnetization using a semi-adiabatic polarization transfer method, PRoton Excited Carbon-13 Image SElected in vivo Localized spectroscopY, or PRECISELY (20), as described recently (23). Editing delays were set to correspond to a heteronuclear coupling constant of $J_{\mathrm{CH}}=137 \mathrm{~Hz}$.

Spectra were analyzed after $3-\mathrm{Hz}$ apodization, zero-filling, and fast-Fourier transform by use of the fitting algorithm supplied by the spectrometer software. To reduce variability, linewidths of ${ }^{13} \mathrm{C}-{ }^{13} \mathrm{C}$ doublets were set to the linewidth of the corresponding center peak, and the fitted frequencies of the ${ }^{13} \mathrm{C}-{ }^{13} \mathrm{C}$ doublets were fixed to be symmetrical to the main resonance, according to the homonuclear ${ }^{13} \mathrm{C}-{ }^{13} \mathrm{C}$ coupling constants. After correction for field frequency drift, the frequencies and linewidths of the fitted peaks were determined on the basis of fit to a spectrum representing the average of $\geq 60$ min of data accumulation. This procedure was justified on the basis of the observation of $<3-\mathrm{Hz}$ changes in ${ }^{1} \mathrm{H}$ spectra (corresponding to $<0.75-\mathrm{Hz}$ changes in ${ }^{13} \mathrm{C}$ spectra) in studies performed over similar time periods with the identical equipment. Convergence of the fit procedure was verified by inspecting the residuals of the fit point by point.

Quantification of integrated ${ }^{13} \mathrm{C}$ signals was performed relative to the signals of $N$-acetyl-aspartate (NAA) at 22.7 (C6) and $54.0 \mathrm{ppm}(\mathrm{C} 2)$ set to correspond to $0.12 \mathrm{mM}$ on the basis of our previous observation of a stable NAA C2 signal at $54.0 \mathrm{ppm}$ (23). Stability of the NAA signals was verified for $2 \mathrm{~h}$ after start of the $\left[1-{ }^{13} \mathrm{C}\right]$ glucose infusion for both the $\mathrm{C} 2$ and C6 resonances (data not shown). This calculation assumes that the ${ }^{1} \mathrm{H}$ saturation factors are identical in vivo, which was supported by inversion-recovery nulled spectroscopy at 4 Tesla (49) and the relatively long repetition time of $3 \mathrm{~s}$. Signal differences due to differential $\mathrm{T}_{2}$ were neglected, because the measured linewidths of $2-3 \mathrm{~Hz}$ implied that $\mathrm{T}_{2}$ is longer than $100 \mathrm{~ms}$, which is much longer than the $\mathrm{T}_{2}$ evolution time of the sequence $(9 \mathrm{~ms})$.

Modeling of compartmentalized neurotransmitter metabolism in the human brain. The time courses were used as the experimental data to fit the model recently proposed in Ref. 23, which is redrawn in Fig. $1 A$. Because the scheme does not explicitly describe the mechanisms by which label is scrambled in the tricarboxylic acid (TCA) cycle, we have added the scheme in Fig. $1 B$.

The scheme in Fig. $1 B$ explicitly accounts for potential finite exchange between the amino acids in the cytosol and the TCA cycle intermediates in the mitochondrion. The differential Eqs. 5-21 that follow are derived by the generalized procedure described in Ref. 23. Label scrambling in the amino acids due to TCA cycle activity was modeled according to the scheme in Fig. $1 B$, derived as a special case of the general model by Chance et al. (10).

Briefly, label derived from the $\mathrm{C} 1$ or $\mathrm{C} 6$ of glucose arrives at the $\mathrm{C} 3$ of pyruvate/lactate, where depending on whether the label enters the TCA cycle via pyruvate carboxylase (flux $\left.V_{\mathrm{PC}}\right)$ or pyruvate dehydrogenase $\left(V_{\mathrm{PDH}}\right)$ reaction, it ultimately is detected in the $\mathrm{C} 4$ or $\mathrm{C} 2$ position of Glu. Label scrambling due to TCA cycle activity results in the $\mathrm{C} 2$ and $\mathrm{C} 3$ of 2-oxoglutarate $(\mathrm{OG})$ receiving label from the $\mathrm{C} 4$ of $\mathrm{OG}$ (Fig. $1 B)$. In neurons, $V_{\mathrm{PC}}$ was neglected, and in astrocytes, con-
A

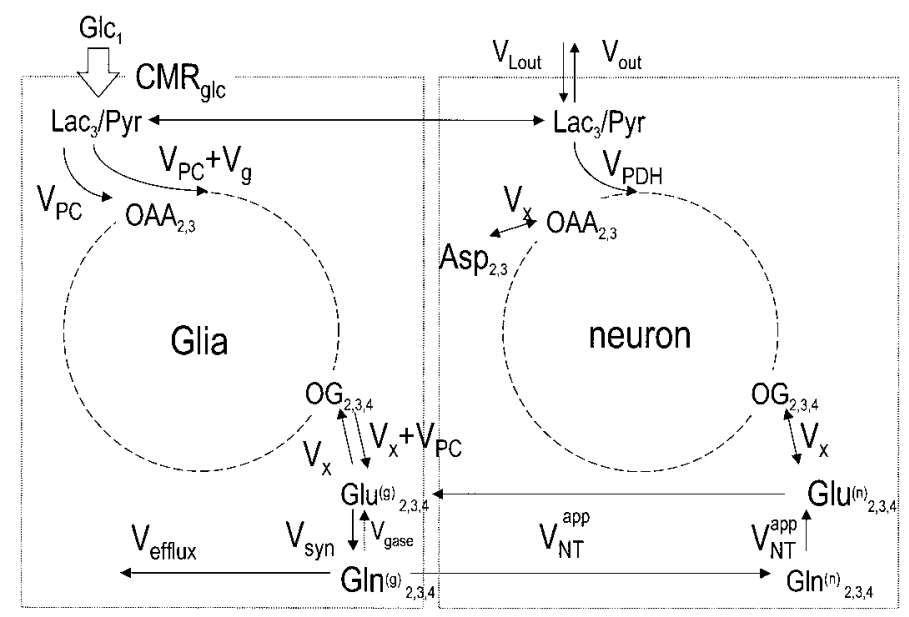

B

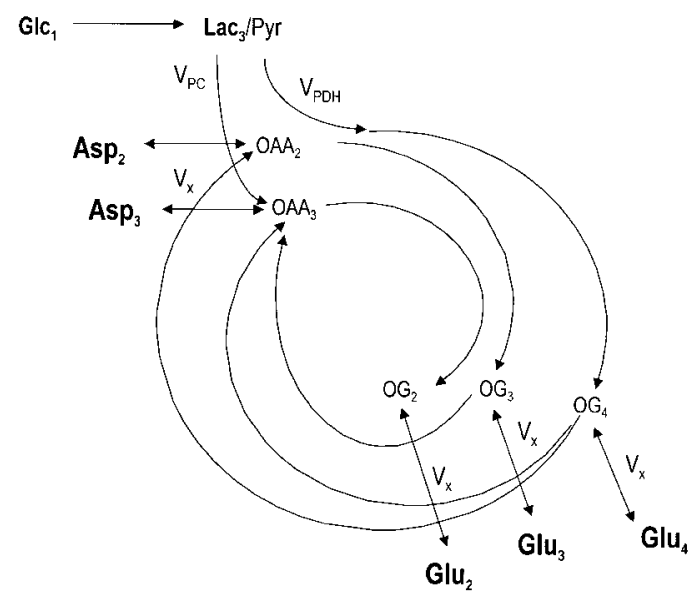

Fig. 1. A: proposed model of cerebral compartmentation based on published enzymatic compartmentation in the brain. Left: glial compartment; right: neuronal compartment. This figure is adapted from one in Ref. 23, with the following abbreviations for metabolic fluxes: $\mathrm{CMR}_{\mathrm{Glc}}$, glucose consumption; $V_{\mathrm{PDH}}$, neuronal tricarboxylic acid (TCA) cycle; $V_{\mathrm{PC}}$, rate of pyruvate carboxylase; $V_{\mathrm{g}}+V_{\mathrm{PC}}$, glial pyruvate dehydrogenase $+V_{\mathrm{PC}} ; V_{\mathrm{x}}$, exchange between cytosolic amino acids and mitochondrial TCA cycle intermediates; $V_{\mathrm{syn}}$, glutamine synthetase; $V_{\mathrm{NT}}$, apparent rate of glutamate neurotransmission; $V_{\text {efflux }}$, loss of glutamine (Gln) from the glial compartment; $V_{\text {out }}$, $V_{\text {Lout }}$, label dilution and exchange of lactate across the blood-brain barrier; $V_{\text {gase }}$, glutaminase rate; $V_{\mathrm{NT}}^{\text {app }}$, rate of Gln flux from the astrocyte to the glutamatergic neuron. Also, $\mathrm{Lac}_{3} / \mathrm{Pyr}, \mathrm{C} 3$ of lactate and pyruvate; $\mathrm{OAA}_{2,3}, \mathrm{C} 2 \& \mathrm{C} 3$ of oxaloacetate; $\mathrm{OG}_{2,3,4}, \mathrm{C} 2,3, \& 4$ of 2-oxoglutarate $(\mathrm{OG})$. $B$ : scheme illustrating label scrambling from $\left[1-{ }^{13} \mathrm{C}\right]$ glucose due to activity of the TCA cycle. Label transfer from OG C3 to OAA C2 at the succinate level is modeled by the bidirectional arrow between OAA C3 and OG C3. Note also the distribution of label including flux through pyruvate carboxylase and pyruvate dehydrogenase and the relationship with cytosolic amino acids. $V_{\mathrm{x}}$ denotes the exchange between mitochondrial TCA cycle intermediates and cytosolic amino acids. In neurons, $V_{\mathrm{PC}}=0$, and in glia, Aspartate (Asp) was assumed to be negligible. Boldface indicates NMR-measurable molecules and respective positions.

servation of mass required that the flux through glial pyruvate dehydrogenase be equal or larger than $V_{\mathrm{PC}}$, which was modeled by setting the flux through glial pyruvate dehydrogenase to $V_{\mathrm{PC}}+V_{\mathrm{g}}$, with $V_{\mathrm{g}} \geq 0$ (Fig. $1 A$ ), where $V_{\mathrm{g}}$ accounts for the difference in flux between glial pyruvate dehydrogenase and pyruvate carboxylase. 
Label accumulation into Gln proceeds almost exclusively in glia because of the exclusive localization of glutamine synthetase (EC 6.3.1.2) in astrocytes (Fig. 1A).

The effect of a sizable brain glucose concentration on the isotope kinetics cannot be completely ignored $(22,43)$. Therefore, we calculated the enrichment of brain glucose from the measurements of plasma glucose concentration and isotopic fraction by use of the reversible Michaelis-Menten model of glucose transport, which has been shown to provide a more consistent depiction of brain glucose concentrations and transport $(12,24)$. The differential equation describing the change in total brain glucose $\left[\mathrm{G}_{\text {brain }}(t)\right]$ and in ${ }^{13} \mathrm{C}$-labeled brain glucose $\left[{ }^{13} \mathrm{G}_{\text {brain }}(t)\right]$ is given by

$$
\begin{aligned}
& \frac{\mathrm{dG}_{\text {brain }}}{\mathrm{d} t}=\mathrm{T}_{\max } \frac{\mathrm{G}_{\text {plasma }}(t)}{K_{\mathrm{t}}+\mathrm{G}_{\text {brain }}(t) / \mathrm{V}_{\mathrm{d}}+\mathrm{G}_{\text {plasma }}(t)} \\
& \quad-\mathrm{T}_{\max } \frac{\mathrm{G}_{\text {brain }}(t)}{\mathrm{V}_{\mathrm{d}}\left[K_{\mathrm{t}}+\mathrm{G}_{\text {plasma }}(t)\right]+\mathrm{G}_{\text {brain }}(t)}-\mathrm{CMR}_{\mathrm{Glc}} \\
& \frac{\mathrm{d}^{13} \mathrm{G}_{\text {brain }}}{\mathrm{d} t}=\mathrm{T}_{\max } \frac{{ }^{13} \mathrm{G}_{\text {plasma }}(t)}{K_{\mathrm{t}}+\mathrm{G}_{\text {brain }}(t) / \mathrm{V}_{\mathrm{d}}+\mathrm{G}_{\text {plasma }}(t)} \\
& -\mathrm{T}_{\max } \frac{{ }^{13} \mathrm{G}_{\text {brain }}(t)}{V_{\mathrm{d}}\left[K_{\mathrm{t}}+\mathrm{G}_{\text {plasma }}(t)\right]+\mathrm{G}_{\text {brain }}(t)}-\mathrm{CMR}_{\mathrm{Glc}} \frac{{ }^{13} \mathrm{G}_{\text {brain }}(t)}{\mathrm{G}_{\text {brain }}(t)}
\end{aligned}
$$

where $K_{\mathrm{t}}$ is the Michaelis-Menten constant of glucose transport, $\mathrm{T}_{\max }$ is the corresponding maximal transport rate, and $\mathrm{CMR}_{\mathrm{Glc}}$ is glucose consumption. For a more detailed description see Ref. 24. Brain glucose is metabolized by glycolysis to pyruvate, which is assumed to be in rapid exchange with lactate, given the high activity of cerebral L-lactate dehydrogenase (EC 1.1.1.27). We assumed cerebral lactate to have the same isotopic enrichment in both cell types because of the small lactate concentration and large distribution volume (55), in agreement with a high lactate transport efficiency (47). Therefore, only one single cerebral rate of glucose consumption was taken into account; this, however, does not assume that all glycolysis occurs in glia.

The rate of label incorporation into cerebral lactate is thus a function of changing fractional enrichment of brain glucose and the metabolic rate $\mathrm{CMR}_{\mathrm{Glc}}$ and the dilution/efflux $V_{\text {out }}$ (29)

$$
\begin{aligned}
\frac{\mathrm{d}^{13} \mathrm{Lac}_{3}}{\mathrm{~d} t}=\mathrm{CMR}_{\mathrm{Glc}} \frac{{ }^{13} \mathrm{Glc}_{1}(t)}{\mathrm{Glc}(t)}+\mathrm{CMR}_{\mathrm{Glc}} \frac{{ }^{13} \mathrm{Glc}_{6}(t)}{\mathrm{Glc}(t)} \\
\quad-\left(2 \mathrm{CMR}_{\mathrm{Glc}(\mathrm{ox})}+V_{\text {out }}\right) \frac{{ }^{13} \mathrm{Lac}_{3}(t)}{\mathrm{Lac}}+V_{\mathrm{Lout}} \mathrm{FE}_{\mathrm{Lac}}
\end{aligned}
$$

This equation assumes that $V_{\text {out }}$ models the exchange of label with unlabeled plasma lactate, whose fractional enrichment is given by $\mathrm{FE}_{\mathrm{Lac}}$, which was assumed to be 0.011 in this study. $\mathrm{CMR}_{\mathrm{Glc}}$ was set to $0.45 \mu \mathrm{mol} \mathrm{g}^{-1} \mathrm{~min}^{-1}$, and oxidative $\mathrm{CMR}_{\mathrm{Glc}}\left[\mathrm{CMR}_{\mathrm{Glc}(\mathrm{ox})}\right]$ was set to $0.97 \mathrm{CMR}_{\mathrm{Glc}}$. Equations 1-3 were solved using a fourth-order Runge-Kutta algorithm based on the measured time course of plasma glucose and its fractional enrichment, yielding the time course of fractional enrichment for lactate $\mathrm{C} 3, \mathrm{Lac}_{3}(t) / \mathrm{Lac}$.

$V_{\text {out }}$ is assumed to be equivalent to label dilution due to pentose phosphate shunt activity and label dilution at the lactate level (32) and, in principle, also at the acetyl-CoA level. Because the brain relies almost entirely on glucose for energy metabolism, and because fatty acid uptake is small and ketone bodies were not detected in our study, we assumed that dilution at the acetyl-CoA level in brain is negligible. Net loss of lactate can be modeled by assuming $V_{\text {Lout }} \leq V_{\text {out }}$. In the resting brain, $V_{\text {Lout }} \sim V_{\text {out }}$, or al- most complete oxidative metabolism of glucose, defined as $2 \mathrm{CMR}_{\mathrm{Glc}}=2 \mathrm{CMR}_{\mathrm{Glc}(\mathrm{ox})}-V_{\text {Lout }}+V_{\text {out }}$.

In our scheme (Fig. $1 A$ ), total $\mathrm{CMR}_{\text {Glc(ox) }}$ (defined as the rate of glucose equivalents entering the TCA cycle) is related to the fluxes in glial and neuronal TCA cycles by the relationship

$$
\mathrm{CMR}_{\mathrm{Glc}(\mathrm{ox})}=\frac{V_{\mathrm{PDH}}+V_{\mathrm{g}}}{2}+V_{\mathrm{PC}}
$$

where $V_{\mathrm{g}}$ denotes the flux through glial pyruvate dehydrogenase corresponding to complete oxidation of pyruvate, i.e., $V_{\mathrm{g}}$ $+V_{\mathrm{PC}}$ is the total flux through glial pyruvate dehydrogenase (as outlined in the scheme in Fig. 1A), $V_{\mathrm{PDH}}$ is the analogous flux in neurons, and $V_{\mathrm{PC}}$ is the rate of net oxaloacetate (OAA) and net citrate formation (anaplerosis). The net carbon compound formed is in our steady-state model removed by net consumption of OG and biosynthesis of Gln.

Throughout this section, the superscript 13 denotes the ${ }^{13} \mathrm{C}$ label, and the numeral subscripts indicate the position at which the label is observed, e.g. ${ }^{13} \mathrm{Glu}_{4}$ denotes the sum of all isotopomers of Glu with ${ }^{13} \mathrm{C}$ label at the $\mathrm{C} 4$ position. The derivation of these and the following differential equations follows from tracer kinetics and is mathematically equivalent to the procedure outlined previously (23) and used in many earlier studies (10, 14, 40, 57).

Because the gluconeogenic capacity, as well as the capacity to generate pyruvate or lactate from amino acids, is generally small in the neuronal compartment (38), we assumed that the net flux of Glu carbon skeletons into the neuronal TCA cycle was negligible compared with $V_{\mathrm{PDH}}$.

The NMR signal represents total tissue Glu concentration, (and Gln, conversely) of which the vesicular neurotransmitter pool is generally viewed to constitute a small fraction. Neglecting the contribution of extracellular Glu (0.004 $\mu \mathrm{mol} / \mathrm{g}$ ) to the NMR signal, the neuronal Glu pool [Glu $\left.{ }^{(\mathrm{n})}\right]$ can be partitioned into a vesicular (small) neurotransmitter signal $\mathrm{Glu}_{\mathrm{NT}}$ plus a metabolic pool Glu met $_{\text {. Based on studies }}$ showing 1) rapid redistribution of label between vesicular and extravesicular Glu (73), 2) that isolation of Glu-containing vesicles requires rapid isolation procedures (58), and 3) that influx of Glu results in simultaneous efflux of Gln from glial cells $(34,48)$, we assumed that the exchange between $\mathrm{Glu}_{\text {met }}$ and $\mathrm{Glu}_{\mathrm{NT}}$ is rapid compared with $V_{\mathrm{NT}}^{\mathrm{app}}$, the rate of Gln flux from the astrocyte to the glutamatergic neuron. For definitions of symbols, see also Fig. $1 A$. In this case, the label incorporation into the observed Glu signal will reflect the label incorporation into the neurotransmitter Glu pool, Glu $_{\mathrm{NT}}$.

The lack of metabolic pathways branching off at the level of neuronal Gln, or $\mathrm{Gln}^{(\mathrm{n})}$, and the metabolic steady-state requirement that no net concentration changes occur, e.g., $\mathrm{dGln}{ }^{(\mathrm{n})} / \mathrm{d} t=0$, imply that the rate across the glial-neuronal interface be $V_{\mathrm{NT}}^{\text {app }}$. Under these assumptions, the rate of unidirectional Glu transport out of the neuron is equal to $V_{\mathrm{NT}}^{\mathrm{app}}$, and the rate of $\mathrm{OG}$ and ${ }^{13} \mathrm{Glu}_{4}^{(\mathrm{n})}$ labeling can be written, accordingly, as

$$
\begin{aligned}
\frac{\mathrm{d}^{13} \mathrm{OG}_{4}^{(\mathrm{n})}}{\mathrm{d} t}=V_{\mathrm{PDH}} & \frac{{ }^{13} \operatorname{Lac}_{3}(t)}{\mathrm{Lac}} \\
& -\left(V_{\mathrm{PDH}}+V_{\mathrm{x}}\right) \frac{{ }^{13} \mathrm{OG}_{4}^{(\mathrm{n})}(t)}{\mathrm{OG}^{(\mathrm{n})}}+V_{\mathrm{x}} \frac{{ }^{13} \mathrm{Glu}_{4}^{(\mathrm{n})}(t)}{\mathrm{Glu}^{(\mathrm{n})}}
\end{aligned}
$$




$$
\begin{aligned}
& \frac{\mathrm{d}^{13} \mathrm{Glu}_{4}^{(\mathrm{n})}}{\mathrm{d} t}=V_{\mathrm{x}} \frac{{ }^{13} \mathrm{OG}_{4}^{(\mathrm{n})}(t)}{\mathrm{OG}^{(\mathrm{n})}} \\
& -\left(V_{\mathrm{x}}+V_{\mathrm{NT}}^{\mathrm{app}}\right) \frac{{ }^{13} \mathrm{Glu}_{4}^{(\mathrm{n})}(t)}{\mathrm{Glu}^{(\mathrm{n})}}+V_{\mathrm{NT}}^{\mathrm{app}} \frac{{ }^{13} \mathrm{Gln}_{4}^{(\mathrm{n})}(t)}{\mathrm{Gln}^{(\mathrm{n})}} \\
& \frac{\mathrm{d}^{13} \mathrm{OG}_{3}^{(\mathrm{n})}}{\mathrm{d} t}=V_{\mathrm{PDH}} \frac{{ }^{13} \mathrm{OAA}_{2}^{(\mathrm{n})}(t)}{\mathrm{OAA}^{(\mathrm{n})}} \\
& \quad-\left(V_{\mathrm{PDH}}+V_{\mathrm{x}}\right) \frac{{ }^{13} \mathrm{OG}_{3}^{(\mathrm{n})}(t)}{\mathrm{OG}^{(\mathrm{n})}}+V_{\mathrm{x}} \frac{{ }^{13} \mathrm{Glu}_{3}^{(\mathrm{n})}(t)}{\mathrm{Glu}^{(\mathrm{n})}} \\
& \frac{\mathrm{d}^{13} \mathrm{Glu}_{3}^{(\mathrm{n})}}{\mathrm{d} t}=V_{\mathrm{x}} \frac{{ }^{13} \mathrm{OG}_{3}^{(\mathrm{n})}(t)}{\mathrm{OG}^{(\mathrm{n})}} \\
& -\left(V_{\mathrm{x}}+V_{\mathrm{NT}}^{\mathrm{app}}\right) \frac{{ }^{13} \mathrm{Glu}_{3}^{(\mathrm{n})}(t)}{\mathrm{Glu}^{(\mathrm{n})}}+V_{\mathrm{NT}}^{\mathrm{app}} \frac{{ }^{13} \mathrm{Gln}_{3}^{(\mathrm{n})}(t)}{\mathrm{Gln}^{(\mathrm{n})}}
\end{aligned}
$$

By equating the forward and backward exchange rates between Glu and OG, we have assumed that net flux of neuronal Glu into the neuronal TCA cycle is negligible compared with the unidirectional exchange rates $\left(V_{\mathrm{x}}\right)$ that describe the exchange rate between (mitochondrial) OG and (cytosolic) Glu (see also Fig. 1). Therefore, $V_{\mathrm{x}}$ is a composite figure that describes the combined effect of glutamate dehydrogenase, aspartate transaminase, and transport across the mitochondrial membranes. Given the slow incorporation of nitrogen into Glu compared with the glutamine amide group (15), glutamate dehydrogenase flux must be small compared with the flux through glutamine synthetase; it was, therefore, neglected. This assumption is also consistent with studies showing a reduced Glu concentration when aspartate transaminase was inhibited (11). The differential equations for $\mathrm{Glu}_{3}$ are equivalent to those for $\mathrm{Glu}_{4}$ and are simply derived by replacing the subscript. Likewise, analog equations can be written for $\mathrm{Glu}_{2}$ simply by replacing the subscript. Label incorporation into OAA, which is in exchange with Asp, is described by the following equations

$$
\begin{aligned}
& \frac{\mathrm{d}^{13} \mathrm{OAA}_{3}^{(\mathrm{n})}}{\mathrm{d} t}= \frac{V_{\mathrm{PDH}}}{2} \frac{{ }^{13} \mathrm{OG}_{4}^{(\mathrm{n})}(t)+{ }^{13} \mathrm{OG}_{3}^{(\mathrm{n})}(t)}{\mathrm{OG}^{(\mathrm{n})}} \\
&-\left(V_{\mathrm{PDH}}+V_{\mathrm{x}}\right) \frac{{ }^{13} \mathrm{OAA}_{3}^{(\mathrm{n})}(t)}{\mathrm{OAA}^{(\mathrm{n})}}+V_{\mathrm{x}} \frac{{ }^{13} \mathrm{Asp}_{3}^{(\mathrm{n})}(t)}{\mathrm{Asp}^{(\mathrm{n})}} \\
& \frac{\mathrm{d}^{13} \mathrm{OAA}_{2}^{(\mathrm{n})}}{\mathrm{d} t}= \frac{V_{\mathrm{PDH}}}{2} \frac{{ }^{13} \mathrm{OG}_{4}^{(\mathrm{n})}(t)}{\mathrm{OG}^{(\mathrm{n})}}-\left(V_{\mathrm{PDH}}+V_{\mathrm{x}}\right) \frac{{ }^{13} \mathrm{OAA}_{2}^{(\mathrm{n})}(t)}{\mathrm{OAA}^{(\mathrm{n})}} \\
& \quad+\frac{V_{\mathrm{PDH}}}{2} \frac{{ }^{13} \mathrm{OG}_{3}^{(\mathrm{n})}(t)}{\mathrm{OG}^{(\mathrm{n})}}+V_{\mathrm{x}} \frac{{ }^{13} \mathrm{Asp}_{2}^{(\mathrm{n})}(t)}{\mathrm{Asp}^{(\mathrm{n})}} \\
& \frac{\mathrm{d}^{13} \mathrm{Asp}_{3}^{(\mathrm{n})}}{\mathrm{d} t}= V_{\mathrm{x}} \frac{{ }^{13} \mathrm{OAA}_{3}^{(\mathrm{n})}(t)}{\mathrm{OAA}^{(\mathrm{n})}}-V_{\mathrm{x}} \frac{{ }^{13} \mathrm{Asp}_{3}^{(\mathrm{n})}(t)}{\mathrm{Asp}^{(\mathrm{n})}} \\
& \frac{\mathrm{d}^{13} \mathrm{Asp}}{\mathrm{d} t}=V_{\mathrm{x}} \frac{{ }^{13} \mathrm{OAA}_{2}^{(\mathrm{n})}(t)}{\mathrm{OAA}^{(\mathrm{n})}}-V_{\mathrm{x}} \frac{{ }^{13} \mathrm{Asp}_{2}^{(\mathrm{n})}(t)}{\mathrm{Asp}^{(\mathrm{n})}}
\end{aligned}
$$

The lack of metabolic pathways branching off at neuronal Gln was based on observation of little or no Gln efflux into the medium of cultured neurons, as shown in, for example, Ref. 38. The rate of change in ${ }^{13} \mathrm{Gln}_{4}^{(\mathrm{n})}$ is thus given by

$$
\frac{\mathrm{d}^{13} \mathrm{Gln}_{4}^{(\mathrm{n})}}{\mathrm{d} t}=V_{\mathrm{NT}}^{\mathrm{app}} \frac{{ }^{13} \mathrm{Gln}_{4}^{(\mathrm{g})}(t)}{\mathrm{Gln}^{(\mathrm{g})}}-V_{\mathrm{NT}}^{\mathrm{app}} \frac{{ }^{13} \mathrm{Gln}_{4}^{(\mathrm{n})}(t)}{\mathrm{G}^{(\mathrm{n})}}
$$

and likewise for the other positions in $\operatorname{Gln}^{(\mathrm{n})}$, because the glutaminase reaction does not change the positional ${ }^{13} \mathrm{C}$ labeling between Gln and Glu.
Glial metabolism: glutamine synthetase and pyruvate carboxylase. In reference to the majority of evidence that links the Glu/Gln interrelationship to excitatory neurotransmission (77), we have denoted the rate from $\mathrm{Gln}^{(\mathrm{n})}$ to $\mathrm{Glu}^{(\mathrm{n})}$ and from $\mathrm{Glu}^{(\mathrm{n})}$ to $\mathrm{Glu}^{(\mathrm{g})}$ as $V_{\mathrm{NT}}^{\mathrm{app}}$, the apparent rate of neurotransmission. In view of the low glutaminase (EC 3.5.1.2) activity in glia (28), we assumed that the glutaminase rate $\left(V_{\text {gase }}\right)$ is negligible compared with $V_{\mathrm{NT}}^{\text {app }}$. Although we assumed in this study that $V_{\text {gase }}=0$ (as indicated by the dashed arrow in Fig. $1 A$ ), the equations below are written to allow for some $V_{\text {gase }}$. The steady-state requirement

$$
V_{\text {syn }}=V_{\mathrm{PC}}+V_{\text {gase }}+V_{\mathrm{NT}}^{\text {app }}
$$

assumes that anaplerosis leads to glial loss of Gln. Loss of Gln from the glial cell to the extracellular space is, in this case, modeled by the term $V_{\text {efflux }}=V_{\mathrm{PC}}$. The rate of ${ }^{13} \mathrm{Gln}_{4}^{(\mathrm{g})}$ labeling is thus given by

$$
\begin{aligned}
& \frac{\mathrm{d}^{13} \mathrm{Gln}_{4}^{(\mathrm{g})}}{\mathrm{d} t}=V_{\mathrm{syn}} \frac{{ }^{13} \mathrm{Glu}_{4}^{(\mathrm{g})}(t)}{\mathrm{Glu}^{(\mathrm{g})}} \\
& \quad-\left(V_{\text {gase }}+V_{\text {efflux }}+V_{\mathrm{NT}}^{\text {app }}\right) \frac{{ }^{13} \mathrm{Gln}_{4}^{(\mathrm{g})}(t)}{\mathrm{Gln}^{(\mathrm{g})}}
\end{aligned}
$$

and equivalent equations can be written for the 2 and 3 positions of glial Gln simply by replacing the subscript 4 with 2 and 3 , respectively

$$
\begin{aligned}
& \frac{\mathrm{d}^{13} \mathrm{Gln}_{3}^{(\mathrm{g})}}{\mathrm{d} t}=V_{\mathrm{syn}} \frac{{ }^{13} \mathrm{Glu}_{3}^{(\mathrm{g})}(t)}{\mathrm{Glu}^{(\mathrm{g})}} \\
& -\left(V_{\text {gase }}+V_{\text {efflux }}+V_{\mathrm{NT}}^{\text {app }}\right) \frac{{ }^{13} \operatorname{Gln}_{3}^{(\mathrm{g})}(t)}{\mathrm{Gln}^{(\mathrm{g})}} \\
& \frac{\mathrm{d}^{13} \mathrm{Gln}_{2}^{(\mathrm{g})}}{\mathrm{d} t}=V_{\mathrm{syn}} \frac{{ }^{13} \mathrm{Glu}_{2}^{(\mathrm{g})}(t)}{\mathrm{Glu}^{(\mathrm{g})}} \\
& -\left(V_{\text {gase }}+V_{\text {efflux }}+V_{\text {NT }}^{\text {app }}\right) \frac{{ }^{13} \mathrm{Gln}_{2}^{(\mathrm{g})}(t)}{\mathrm{G}^{(\mathrm{g})}}
\end{aligned}
$$

In addition to label derived from neuronal $\mathrm{Glu}^{(\mathrm{n})}$, label can be incorporated into glial glutamate $\left[\mathrm{Glu}^{(\mathrm{g})}\right]$ from the glial TCA cycle, the rate of which is given by $V_{\mathrm{g}}$ (Fig. 1). Pyruvate carboxylase (PC, EC 6.4.1.1) transfers label from pyruvate $\mathrm{C} 3$ to OAA $\mathrm{C} 3$ in the glial compartment. In this model, reverse flux from OAA to fumarate was neglected, on the basis of previous reports suggesting a substantial difference in labeling at the $\mathrm{C} 1$ and $\mathrm{C} 4$ position of OAA (31), which is supported by differential labeling of Glu C2 and C3 in astrocytes (41). Neglecting any backflux to fumarate underestimates the pyruvate carboxylase flux when assessed from the differential labeling of the C2 and C3 positions in Glu and Gln. Given the small pool size of cerebral OAA and most TCA cycle intermediates, label equilibration is assumed to be relatively fast until it reaches OG. The small pool size of glial $\mathrm{Glu}^{(\mathrm{g})}$ relative to the high activity of the malate-aspartate shuttle is assumed to result in rapid label equilibration of $\mathrm{Glu}^{(\mathrm{g})}$ relative to $\mathrm{OAA}^{(\mathrm{g})} \cdot \mathrm{Glu}_{2}^{(\mathrm{g})}$ is also labeled from neuronal $\mathrm{Glu}_{2}^{(\mathrm{n})}$ as well as from glial $\mathrm{Glu}_{4}^{(\mathrm{g})}$ on subsequent turns of the TCA cycle.

The rate of lactate labeling is calculated as described in $E q .3$ and set to that of pyruvate, which is the label precursor for acetyl-CoA; thus 


$$
\begin{aligned}
& \frac{\mathrm{d}^{13} \mathrm{OG}_{4}^{(\mathrm{g})}}{\mathrm{d} t}=\left(V_{\mathrm{g}}+V_{\mathrm{PC}}\right) \frac{{ }^{13} \mathrm{Lac}_{3}(t)}{\mathrm{Lac}} \\
& -\left(V_{\mathrm{g}}+V_{\mathrm{PC}}+\mathrm{V}_{\mathrm{x}}\right) \frac{{ }^{13} \mathrm{OG}_{4}^{(\mathrm{g})}(t)}{\mathrm{OG}^{(\mathrm{g})}}+V_{\mathrm{x}} \frac{{ }^{13} \mathrm{Glu}_{4}^{(\mathrm{g})}(t)}{\mathrm{Glu}^{(\mathrm{g})}} \\
& \frac{\mathrm{d}^{13} \mathrm{Glu}_{4}^{(\mathrm{g})}}{\mathrm{d} t}=V_{\mathrm{x}} \frac{{ }^{13} \mathrm{OG}_{4}^{(\mathrm{g})}(t)}{\mathrm{OG}^{(\mathrm{g})}}-\left(\mathrm{V}_{\mathrm{x}}+V_{\mathrm{syn}}\right) \frac{{ }^{13} \mathrm{Glu}_{4}^{(\mathrm{g})}(t)}{\mathrm{Glu}^{(\mathrm{g})}} \\
& +V_{\text {gase }} \frac{{ }^{13} \mathrm{Gln}_{4}^{(\mathrm{g})}(t)}{\mathrm{Gln}^{(\mathrm{g})}}+\mathrm{V}_{\mathrm{NT}}^{\mathrm{app}} \frac{{ }^{13} \mathrm{Gln}_{4}^{(\mathrm{n})}(t)}{\mathrm{Glu}^{(\mathrm{n})}} \\
& \frac{\mathrm{d}^{13} \mathrm{OAA}_{2}^{(\mathrm{g})}}{\mathrm{d} t}=\frac{V_{\mathrm{g}}}{2} \frac{{ }^{13} \mathrm{OG}_{4}^{(\mathrm{g})}(t)+{ }^{13} \mathrm{OG}_{3}^{(\mathrm{g})}(t)}{\mathrm{OG}^{(\mathrm{g})}}-V_{\mathrm{g}} \frac{{ }^{13} \mathrm{OAA}_{2}^{(\mathrm{g})}(t)}{\mathrm{OAA}^{(\mathrm{g})}} \\
& \frac{\mathrm{d}^{13} \mathrm{OAA}_{3}^{(\mathrm{g})}}{\mathrm{d} t}=V_{\mathrm{PC}} \frac{{ }^{13} \mathrm{Lac}_{3}(t)}{\mathrm{Lac}}+\frac{V_{\mathrm{g}}}{2} \frac{{ }^{13} \mathrm{OG}_{4}^{(\mathrm{g})}(t)}{\mathrm{OG}^{(\mathrm{g})}} \\
& -\left(V_{\mathrm{g}}+V_{\mathrm{PC}}\right) \frac{{ }^{13} \mathrm{OAA}_{3}^{(\mathrm{g})}(t)}{\mathrm{OAA}^{(\mathrm{g})}}+\frac{V_{\mathrm{g}}}{2} \frac{{ }^{13} \mathrm{OG}_{3}^{(\mathrm{g})}(t)}{\mathrm{OG}^{(\mathrm{g})}} \\
& \frac{\mathrm{d}^{13} \mathrm{OG}_{3}^{(\mathrm{g})}}{\mathrm{d} t}=\left(V_{\mathrm{g}}+V_{\mathrm{PC}}\right) \frac{{ }^{13} \mathrm{OAA}_{2}^{(\mathrm{g})}(t)}{\mathrm{OAA}^{(\mathrm{g})}} \\
& -\left(V_{\mathrm{g}}+V_{\mathrm{PC}}+V_{\mathrm{x}}\right) \frac{{ }^{13} \mathrm{OG}_{3}^{(\mathrm{g})}(t)}{\mathrm{OG}^{(\mathrm{g})}}+V_{\mathrm{x}} \frac{{ }^{13} \mathrm{Glu}_{3}^{(\mathrm{g})}(t)}{\mathrm{Glu}^{(\mathrm{g})}}
\end{aligned}
$$

Numerical procedures. The cerebral $\mathrm{Glu}^{(\mathrm{g})}+\mathrm{Glu}^{(\mathrm{n})}$ pool size labeled by $\left[{ }^{13} \mathrm{C}\right]$ glucose was estimated at $5.7 \mu \mathrm{mol} / \mathrm{g}$, in agreement with previous studies $(53,54,56)$, from the amount of ${ }^{13} \mathrm{C}$-labeled Glu signal divided by the fractional enrichment determined from the ${ }^{13} \mathrm{C}-{ }^{13} \mathrm{C}$ isotopomers as described previously $(21,37,40)$. Likewise, the cerebral aspartate pool was estimated at $1.5 \mu \mathrm{mol} / \mathrm{g}$, and this neurotransmitter was assumed to be mainly in the neuronal compartment.

The set of differential equations (see Eqs. 5-21) was solved, and ${ }^{13}\left[\mathrm{Glu}^{(\mathrm{n})}+\mathrm{Glu}^{(\mathrm{g})}\right]_{2,3,4}$ and ${ }^{13}\left[\mathrm{Gln}^{(\mathrm{n})}+\mathrm{Gln}^{(\mathrm{g})}\right]_{2,3,4}$ were simultaneously fitted using commercially available software (SAAM II, The SAAM Institute, Seattle, WA) to the separately measured time courses of Glu C4 and Gln C4 as well as the $\mathrm{C} 2$ and $\mathrm{C} 3$ positions. In addition, we included the combined signal of Asp C2 and C3 in the modeling, Asp 23 , because the smaller pool size of Asp makes the labeling curve less dependent on the exchange $V_{\mathrm{x}}$ compared with the rate of OAA labeling.

All metabolite pools [except for cerebral glucose $\left(\mathrm{Glc}_{\text {brain }}\right)$ ] were assumed to be constant during the duration of the $\left[{ }^{13} \mathrm{C}\right]$ glucose infusions: $14 \%$ of the total glutamate pool was assumed to be in the glial compartment; see Ref. 17 and references therein. Consistent with most evidence (51), we assumed that the neuronal Gln, Gln ${ }^{(\mathrm{n})}$, was small (e.g., 0.2 $\mu \mathrm{mol} / \mathrm{g}$ ), and we verified that this assumption did not influence substantially the labeling time course of Gln. The glutamine pool, Gln ${ }^{(\mathrm{n})}+\mathrm{Gln}(\mathrm{g})$, turned over by $\left[{ }^{13} \mathrm{C}\right]$ glucose metabolism, was estimated at $1.7 \mu \mathrm{mol} / \mathrm{g}$ with the same methods as for Glu. We assumed cerebral OG and OAA pools to be very small, i.e., $\mathrm{OG}^{(\mathrm{n})}=\mathrm{OG}^{(\mathrm{g})}=\mathrm{OAA}^{(\mathrm{n})}=\mathrm{OAA}^{(\mathrm{g})}=0.1$ $\mu \mathrm{mol} / \mathrm{g}$. The cerebral lactate pool was set to a fixed value of $1.0 \mu \mathrm{mol} / \mathrm{g}$. The pool sizes of other glycolytic and TCA cycle intermediates were also assumed to be small and without effect on isotope kinetics; they were validated to be without effect on the conclusions of this paper up to a total mass of several micromoles per gram. On the basis of our inability to detect signals from TCA cycle intermediates, even when summing spectra over extended measurement periods from all measured subjects, we assumed the pool sizes to be below $0.05 \mu \mathrm{mol} / \mathrm{g}$, which we verified to have a negligible impact on the calculated fluxes (not shown).

The following rates were varied to achieve the best fit to the data: $V_{\mathrm{PDH}}, V_{\mathrm{x}}, V_{\text {out }}, V_{\mathrm{NT}}, V_{\mathrm{g}}, V_{\mathrm{PC}}$. All fluxes were constrained to be positive in the fitting process. To take into account that the malate-aspartate shuttle is the major mechanism by which the brain maintains the cytosolic redox state under normoxic conditions, we constrained the exchange rate $V_{\mathrm{x}}$ to be equal or greater than the pyruvate dehydrogenase flux, $V_{\mathrm{PDH}}$.

\section{RESULTS}

The improved sensitivity achieved at 4 Tesla was used to reduce the volume of interest being investigated and to achieve localization to a metabolically more homogenous area in the human brain. Figure 2 illustrates the excellent sensitivity achieved with our approach. The spectrum was acquired $1 \mathrm{~h}$ after the start of $\left[1-{ }^{13} \mathrm{C}\right]$ glucose infusion and represents data collection corresponding to $45 \mathrm{~min}$ from a volume of 45 $\mathrm{ml}$. In addition to the three dominant resonances from Glu, resolved peaks were detected from the corresponding three positions in Gln, and resonances from NAA and GABA were routinely observed. Furthermore, the resolution and sensitivity afforded the simultaneous

\section{Glu C4}

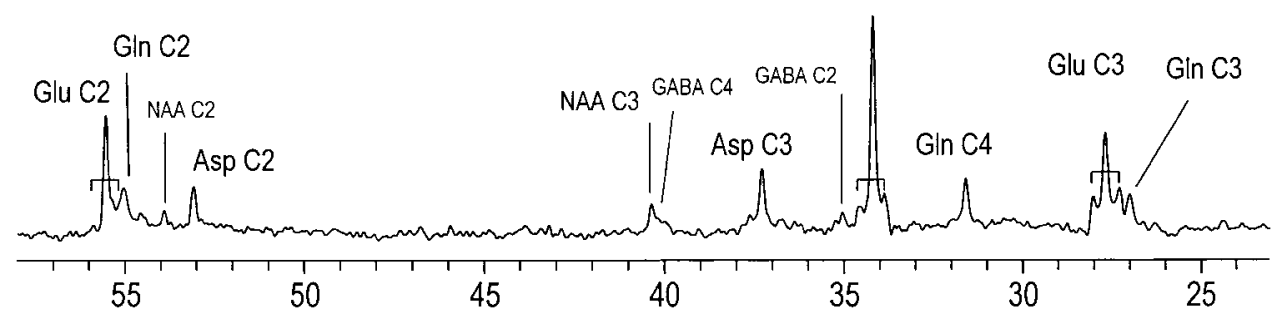

Fig. $2 .{ }^{13} \mathrm{C}$ NMR detection of label incorporation into cytosolic amino acids in a 45 -ml volume in the human occipital lobe at 4 Tesla. This is a representative spectrum obtained from a $3 \times 3 \times 5-\mathrm{cm}^{3}$ volume in the human visual cortex in $45 \mathrm{~min}$. Resonance assignments are as follows: Glu C2 at $55.6 \mathrm{ppm}$, Gln C2 at $55.0 \mathrm{ppm}$, $N$-acetyl-aspartate (NAA) C2 at $54.0 \mathrm{ppm}$, Asp C2 at $53.7 \mathrm{ppm}$, NAA C3 at $40.5 \mathrm{ppm}$, GABA C4 at $40.45 \mathrm{ppm}$, Asp C3 at $37.6 \mathrm{ppm}$, GABA C2 at $35.3 \mathrm{ppm}$, Glu C4 at $34.2 \mathrm{ppm}$, Gln C4 at $31.7 \mathrm{ppm}$, Glu C3 at $28.0 \mathrm{ppm}$, and Gln C3 at $27.7 \mathrm{ppm}$. In addition to these resonances, those ascribed to the homonuclear ${ }^{13} \mathrm{C}-{ }^{13} \mathrm{C}$ coupling were readily detected at positions of all Glu resonances (brackets). The spectrum was processed with a mild Lorentz-to-Gauss apodization $(3 \mathrm{~Hz})$ and is shown without baseline correction. 
A

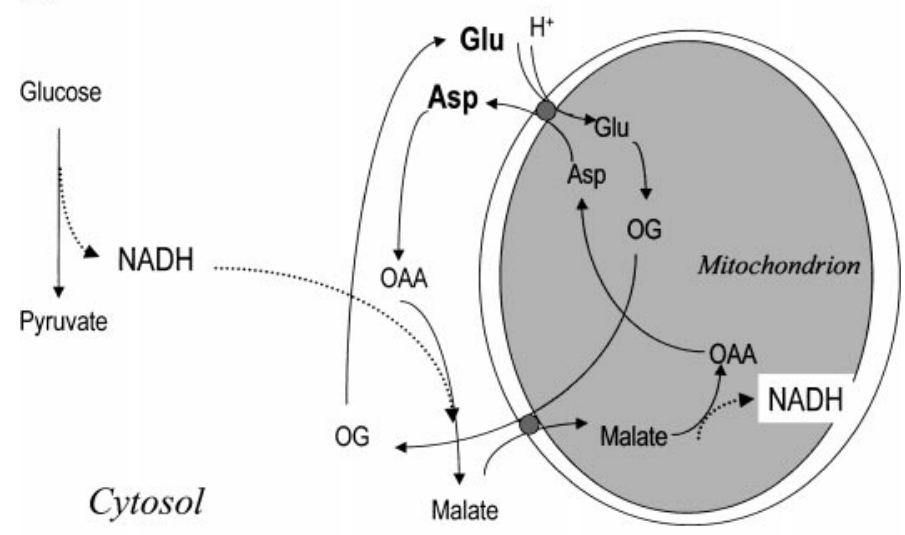

$\mathrm{B}$

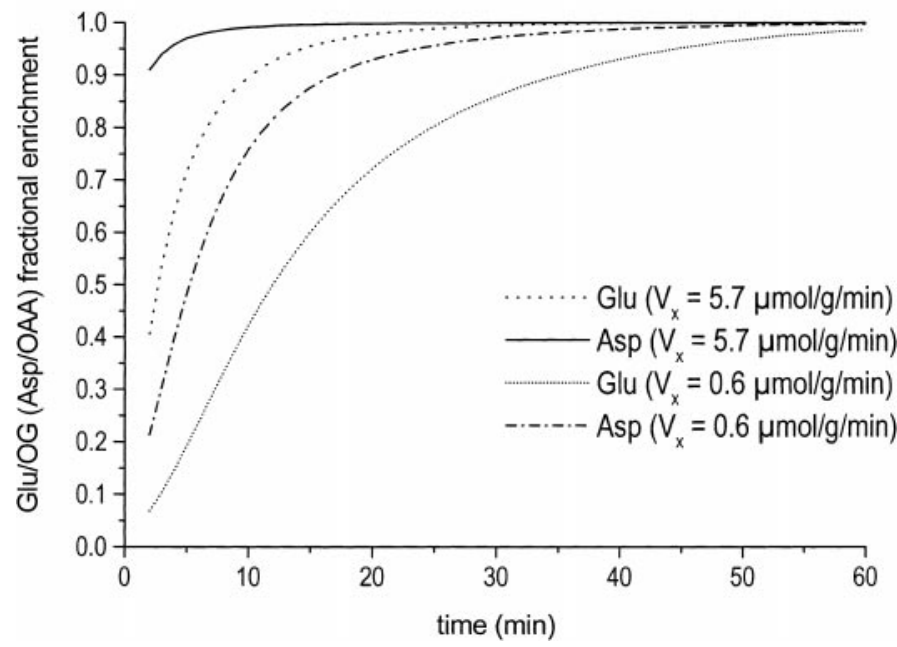

Fig. 3. A: fluxes participating in the malate-aspartate shuttle (adapted from Stryer). The overall flux between mitochondrial OG/ OAA and cytosolic Asp/Glu is modeled by $V_{\mathrm{x}}$. B: to illustrate that the pool size does affect the fidelity by which the corresponding amino acid reflects the rate of labeling of its corresponding TCA cycle intermediate, the label in Asp relative to OAA (dotted curves) was compared with the label in Glu C4 relative to OG C4 (solid curves) for $V_{\mathrm{x}}=5.7$ and $0.55 \mu \mathrm{mol} \cdot \mathrm{g}^{-1} \cdot \mathrm{min}^{-1}$, assuming $V_{\mathrm{PDH}}=0.7$ $\mu \mathrm{mol} \cdot \mathrm{g}^{-1} \cdot \mathrm{min}^{-1}$. Concentrations of the participating amino acids were assumed in this simulation to be $5.7 \mu \mathrm{mol} / \mathrm{g}$ for Glu and 1.5 $\mu \mathrm{mol} / \mathrm{g}$ for Asp.

detection of the homonuclear isotopomers in all three Glu resonances, $\mathrm{C} 2, \mathrm{C} 3$, and $\mathrm{C} 4$.

The spectral data shown in Fig. 2 exemplifies the spectral resolution and suppression of extraneous lipid signal achieved in our study. The resonance intensity for Glu C2, C3, C4 and Gln C2, C3, C4, as well as Asp $\mathrm{C} 2$ and $\mathrm{C} 3$, was determined with a temporal resolution of $15 \mathrm{~min}$, resulting in eight simultaneously recorded time courses of label incorporation into cytosolic amino acids. To improve sensitivity, the labeling curves for aspartate C2 and C3 were averaged and accordingly fitted. Intersubject reproducibility of ${ }^{13} \mathrm{C}$ label incorporation was evaluated from the standard deviation, which was on average $0.1 \mu \mathrm{mol} / \mathrm{g}$.

One major goal of this study was to assess the rate of label exchange between the cytosolic amino acids and their mitochondrial TCA cycle counterparts. This exchange is mediated by the malate-aspartate shuttle (Fig. 3A), which provides a mechanism by which Asp and Glu can be labeled from the TCA cycle through transport of Asp and Glu by the Asp/Glu antiporter (11, $36)$. On the basis of this mechanism, we analyzed the exchange between Asp and OAA as well as between Glu and OG with a single reaction rate, $V_{\mathrm{x}}$. The use of the label incorporation into the amino acids ideally assumes that the rate of label incorporation into the cytosolic amino acids is a good approximation of label incorporation into the metabolic counterpart, e.g., OG in the mitochondrion. However, as stated previously, this assumption generally is true only when the exchange between OG and Glu is fast compared with the TCA cycle flux (45). In addition, as shown in Fig. $3 B$, the accuracy by which the amino acid represents the label incorporation into the TCA cycle intermediate also depends on the relative pool sizes. For example, Asp, whose concentration is at least three times less than that of Glu, much more closely represents the fractional enrichment of OAA (dotted curves in Fig. $3 B$ ) at an otherwise equal relative rate $V_{\mathrm{x}} / V_{\mathrm{PDH}}$, whereas Glu labeling is a much poorer indicator of the corresponding OG labeling (solid curves in Fig. 3B). The effect of assuming widely varying $V_{\mathrm{x}}$ had a quantitatively negligible impact on calculating the TCA cycle flux from the measurement of Asp C2+C3 $\left(\mathrm{Asp}_{23}\right)$ alone (second column in Table 1). On the other hand, the measurement from Glu C4 $\left(\mathrm{Glu}_{4}\right)$ alone illustrates a more profound effect of the assumed value of $V_{\mathrm{x}}$ on the derived TCA cycle flux, as shown in the third column of Table 1.

The model proposed in Ref. 23 and shown in the scheme in Fig. $1 A$ was fitted to the curves showing label incorporation into Glu C4, C3, and C2 as well as Gln C2, C3, and C4 and Asp C2 and C3 (Fig. 4). The fits resulted in a covariance matrix whose normalized offdiagonal elements were in magnitude $<0.6$ for all but one element. The resulting fitted fluxes are shown in Table 2, along with the normalized covariance matrix in Table 3. Because glucose is the dominant fuel for generation of energy in brain, the fitting was constrained, in that $V_{\mathrm{x}}$ was not allowed below the minimum required flux by the malate-aspartate shuttle,

Table 1. TCA cycle flux as a function of rate of exchange, measured from Asp C2+C3 and Glu C4

\begin{tabular}{lcc}
\hline \hline & Asp $_{23}$ & $\mathrm{Glu}_{4}$ \\
\hline$V_{\mathrm{x}}=57 \mu \mathrm{mol} \cdot \mathrm{g}^{-1} \cdot \mathrm{min}^{-1 *}$ & 1.04 & 0.53 \\
$V_{\mathrm{x}}=10 \mu \mathrm{mol} \cdot \mathrm{g}^{-1} \cdot \mathrm{min}^{-1}$ & 1.04 & 0.55 \\
$V_{\mathrm{x}}=2 \mu \mathrm{mol} \cdot \mathrm{g}^{-1} \cdot \mathrm{min}^{-1}$ & 1.03 & 0.65 \\
$V_{\mathrm{x}}=1 \mu \mathrm{mol} \cdot \mathrm{g}^{-1} \cdot \mathrm{min}^{-1}$ & 1.01 & 0.83 \\
$V_{\mathrm{x}}=0.75 \mu \mathrm{mol} \cdot \mathrm{g}^{-1} \cdot \mathrm{min}^{-1}$ & 1.00 & 1.00 \\
\hline
\end{tabular}

Tricarboxylic acid (TCA) cycle flux $\left(V_{\mathrm{PDH}}\right)$ as a function of the exchange rate $\left(V_{\mathrm{x}}\right)$ measured from the $\mathrm{C} 2$ and $\mathrm{C} 3$ of aspartate $\left(\mathrm{Asp}_{23}\right)$ and the $\mathrm{C} 4$ of glutamate $\left(\mathrm{Glu}_{4}\right) . V_{\mathrm{PDH}}$ is obtained by fitting the flux of dilution/efflux and that of pyruvate dehydrogenase, but keeping other fluxes fixed at values reported in Table 2 and dividing them by $V_{\mathrm{PDH}}$ obtained at $V_{x}=0.75 \mathrm{\mu mol} \cdot \mathrm{g}^{-1} \cdot \mathrm{min}^{-1}$. $*$ Value previously published in Ref. 45. 


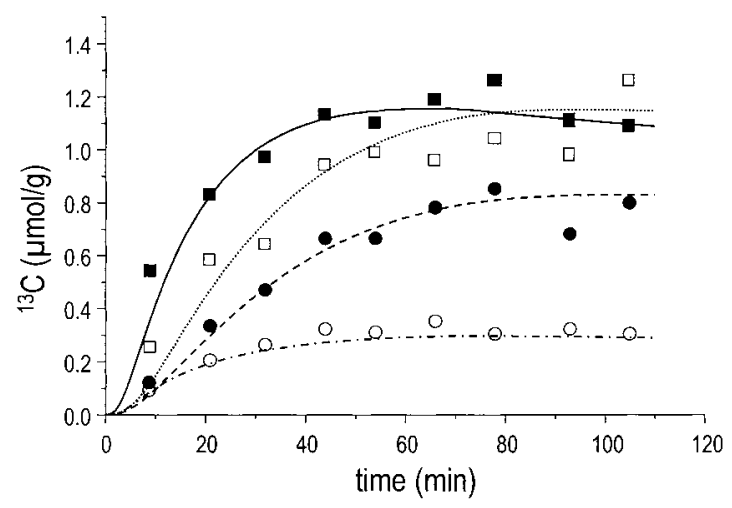

$\rightarrow$ GluC4

---GluC3

……… GluC2

$\cdot \cdot \cdot \operatorname{Asp} 23$

B

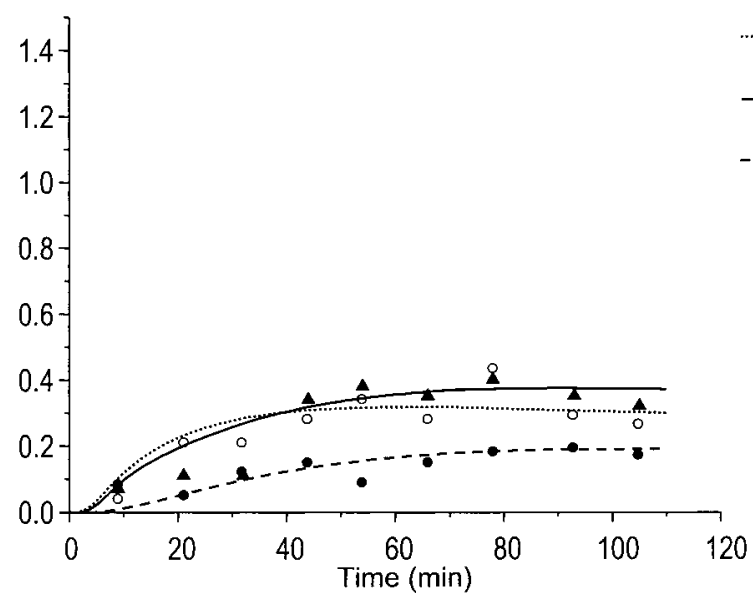

Fig. 4. Observed rates of label incorporation into the main amino acids Glu, Gln, and Asp. Lines represent the best fit of model shown schematically in Fig. $1 A$.

which was assumed to be $V_{\mathrm{PDH}}$, where the fitting process converged.

Provided that flux through glutamine synthetase is exclusively due to the flux from neuronal $\mathrm{Glu}^{(\mathrm{n})}$, Gln should be equally labeled relative to Glu at each carbon atom. Table 4 shows the relative amount of ${ }^{13} \mathrm{C}$ NMR signal at the $\mathrm{C} 2, \mathrm{C} 3$, and $\mathrm{C} 4$ positions determined 60-120 min after the start of the glucose infusion, which was found to be measurably higher at the C2 compared with the $\mathrm{C} 3$ and $\mathrm{C} 4$ positions $(P<0.01)$. In addition to the different isotopomer populations in Gln relative to Glu, fitting to the label incorporation curves also indicated a substantial contribution of pyruvate carboxylase to the total flux through glutamine synthetase.

\section{DISCUSSION}

In the present study we have for the first time comprehensively measured and analyzed multiple curves of label incorporation into resonances from three different amino acids in the human brain. The inclusion of the amino acid Asp with a much lower concentration than Glu helped to reduce the mathematical covariance between fitted fluxes compared with that present in previous studies $(45,76)$, as judged from Table 3 and Fig. 3B. Even higher sensitivity can be obtained, for example by higher static field strength (such as 7 Tesla) and by increasing the fractional enrichment of the amino acids through the use of multiply labeled glucose, e.g., $\left[1,6-{ }^{13} \mathrm{C}_{2}\right]$ glucose. It should then be possible to achieve much more robust measures of TCA cycle flux than through the measurement from Glu alone, as suggested by the comparisons presented in Fig. $3 B$ and Table 1. Nevertheless, some of the advances presented in this study were achieved on the basis of the improved sensitivity afforded by the use of a human 4-Tesla system. The sensitivity shown in Fig. 2 obtained from a $45-\mathrm{ml}$ volume in $45 \mathrm{~min}$ is comparable to that of a $144-\mathrm{ml}$ volume at 2.1 Tesla in 60 min (65). This illustrates the substantial gain in sensitivity (approximately threefold) achieved at 4 Tesla compared with 2.1 Tesla. The reduced volume size measured in this study currently is the smallest reported for this type of experiment. Thus partial volume effects were smaller because of a higher contribution of gray matter to the overall signal. In addition to the size, the location of the voxel assured that signals were acquired predominantly from gray matter, consistent with the very high cerebral blood flow and the high metabolic glucose consumption rate measured by fluorodeoxyglucose and $\left[{ }^{11} \mathrm{C}\right]$ glucose positron emission tomography (PET) in this region (70). Furthermore, ${ }^{1} \mathrm{H}$ MRS (59) consistently showed a choline-to-creatine ratio associated with a predominantly gray matter composition of the human occipital lobe (unpublished data), according to Hetherington et al. (27). We therefore assumed that interindividual differences in tissue composition were minimized for the volumes used in the present study.

Our study indicates a rate of neuronal TCA cycle flux $\left(V_{\mathrm{PDH}}\right.$, Fig. $1 A$ ) of $0.57 \mu \mathrm{mol} \cdot \mathrm{g}^{-1} \cdot \mathrm{min}^{-1}$ (Table 2). The small but measurable glial pyruvate dehydrogenase flux, $V_{\mathrm{PC}}+V_{\mathrm{g}}$, is consistent with active glial metabolism of acetate (74). Incorporating the small glial TCA cycle flux rate of $0.06 \mu \mathrm{mol} \cdot \mathrm{g}^{-1} \cdot \mathrm{min}^{-1}$ and the rate of pyruvate carboxylase, $V_{\mathrm{PC}}$, of $0.09 \mu \mathrm{mol} \cdot \mathrm{g}^{-1} \cdot \mathrm{min}^{-1}$, an oxidative glucose consumption rate $\left[\mathrm{CMR}_{\mathrm{Glc(ox)}}\right]$ of $0.41 \pm 0.03 \mu \mathrm{mol} \cdot \mathrm{g}^{-1} \cdot \mathrm{min}^{-1}$ was derived, which is in excellent agreement with PET measurements of total $\mathrm{CMR}_{\mathrm{Glc}}$ in resting gray matter (70) and the nearly complete oxidation of cerebral glucose under resting conditions.

Table 2. Derived metabolic fluxes

\begin{tabular}{cccccccc}
\hline \hline$V_{\mathrm{PDH}}$ & $V_{\mathrm{x}}$ & $\mathrm{CMR}_{\mathrm{Glc}(\mathrm{ox})}$ & $V_{\mathrm{NT}}$ & $V_{\mathrm{PC}}$ & $V_{\mathrm{g}}$ & $V_{\text {out }}$ & $V_{\mathrm{syn}}$ \\
\hline $0.57 \pm 0.06$ & $0.57 \pm 0.19$ & $0.41 \pm 0.03$ & $0.17 \pm 0.05$ & $0.09 \pm 0.02$ & $0.06 \pm 0.04$ & $0.41 \pm 0.04$ & $0.26 \pm 0.06$ \\
\hline
\end{tabular}

Metabolic fluxes $\left(\mu \mathrm{mol} \cdot \mathrm{g}^{-1} \cdot \mathrm{min}^{-1}\right)$ with reference to model shown in Fig. 1A; see definitions of fluxes in legend to Fig. 1. 
Table 3. Average normalized covariance matrix for fluxes derived in Table 2

\begin{tabular}{|c|c|c|c|c|c|}
\hline$V_{\mathrm{NT}}$ & $V_{\text {out }}$ & $V_{\mathrm{g}}$ & $V_{\mathrm{PC}}$ & $V_{\text {PDH }}$ & $V_{\mathrm{x}}$ \\
\hline 1.00 & $\begin{array}{c}-0.09 \pm 0.12 \\
1.00\end{array}$ & $\begin{array}{c}-0.35 \pm 0.18 \\
0.38 \pm 0.17 \\
1.00\end{array}$ & $\begin{array}{c}-0.27 \pm 0.18 \\
0.39 \pm 0.14 \\
0.79 \pm 0.03 \\
1.00\end{array}$ & $\begin{array}{r}0.31 \pm 0.15 \\
0.52 \pm 0.26 \\
-0.54 \pm 0.15 \\
-0.39 \pm 0.24 \\
1.00\end{array}$ & $\begin{array}{r}0.27 \pm 0.11 \\
-0.32 \pm 0.17 \\
-0.54 \pm 0.10 \\
-0.27 \pm 0.34 \\
-0.25 \pm 0.26 \\
1.00\end{array}$ \\
\hline
\end{tabular}

In principle, the metabolic relationship between Glu and Gln implies that the relative distribution of label in the different positions of Gln must be the same as that of Glu, with the assumption that the large (neuronal) pool is the dominant source of label for the (glial) pool of Gln. Any differential extent of labeling in brain Gln therefore implies that other, glial, reactions, such as pyruvate carboxylase, must contribute significantly to the flux through glutamine synthetase. In this investigation, we extended our previous work to measure pyruvate carboxylase activity in the human brain by use of a single, isotopically enriched substrate that can be obtained at comparatively low cost, namely D-[1${ }^{13} \mathrm{C}$ ]glucose. Our measurement is in excellent agreement with previous studies using $\mathrm{D}-\left[\mathrm{U}^{13} \mathrm{C}_{6}\right]$ glucose (37) and our previous report from larger volumes in the human brain (23). The $95 \%$ confidence interval for the rate of pyruvate carboxylation in this and our previous study (23) overlaps well with the upper limit of a more recent study, which assessed the rate of anaplerosis from the Glu C4 and Gln C4 resonances only (65). However, when label incorporation is measured into only one or two positions, the complexity of cerebral energy metabolism is likely to result in ambiguous numerical solutions because four different fluxes were simultaneously fitted. Consequently, the previous assertion of a very small activity of pyruvate carboxylase must be considered with caution.

It should be stressed in this context that our modeling does not assume that the rate of pyruvate carboxylation must result in a net loss of Gln into the bloodstream. Because Gln is the single most concentrated amino acid in the cerebrospinal fluid, it can be metabolized by many other reactions and compartments. Regardless of the specific quantitative value of pyruvate carboxylation, the consistent observation that isotopomers of Glu and Gln are not identical suggests that the Glu/Gln interconversion is not the sole source of flux through glutamine synthetase, in that pyruvate carboxylation can contribute substantially to the labeling pattern in glial Gln. In fact, our study suggests that the flux from (neuronal) Glu to (glial) Gln is only on the

Table 4. Relative label incorporation into Gln relative to Glu at the respective position

\begin{tabular}{lccc}
\hline \hline & $\mathrm{C} 2$ & $\mathrm{C} 3$ & $\mathrm{C} 4$ \\
\hline $\mathrm{Gln} / \mathrm{Glu}$ & $0.41 \pm 0.02$ & $0.28 \pm 0.04^{*}$ & $0.30 \pm 0.01^{*}$ \\
\hline $\begin{array}{l}\text { Values are means } \pm \mathrm{SE} ; n \\
\text { the C2 position. }\end{array}$ & $6 . * P<0.01$ vs. ratio measured at
\end{tabular}

order of $41 \pm 14 \%$ of the oxidative glucose consumption, which is much lower than the 1:1 stoichiometric relationship that has been claimed on the basis of analysis of $\mathrm{C} 4$ time courses only in whole rat head studies (67). It should also be emphasized that pyruvate carboxylation that leads to net formation of Glu, and eventually Gln, is energetically favorable, because each Gln molecule synthesized from glucose via pyruvate carboxylase (one-half of the glucose is used in the form of pyruvate for formation of OAA; the other onehalf is used for the formation of acetyl-CoA needed for the net formation of citrate required to generate the extra OG required for the net synthesis of Gln) generates a total of $4 \mathrm{NADH}$ molecules (two are produced by glycolysis, one by pyruvate dehydrogenase, and one by isocitrate dehydrogenase, and two ATP are formed by glycolysis and two are used by PC and glutamine synthetase), resulting in a net formation of $\sim 10$ ATP molecules (assuming a $\mathrm{P} / \mathrm{O}$ ratio of 2.5 ), thereby removing two $\mathrm{NH}_{4}^{+}$, which is an energetically highly favorable reaction compared with the purely anaerobic combustion of glucose. Including the glial TCA cycle flux of $V_{\mathrm{g}}=0.06 \mu \mathrm{mol} \cdot \mathrm{g}^{-1} \cdot \mathrm{min}^{-1}$ (Table 2 ), we calculate an oxidative ATP production of $V_{\mathrm{g}} \times 32+V_{\mathrm{PC}} \times 10$, which represents $87 \pm 5 \%$ of the glial ATP generation, because the term $\mathrm{CMR}_{\mathrm{Glc}} \times 2$ is added when we assume that all of the glycolysis is confined to the glial compartment. This calculation results in $3 \mu \mathrm{mol} \cdot \mathrm{g}^{-1}$. $\min ^{-1}$ of ATP produced in the glial compartment, a rate that can easily sustain the energy requirements for maintaining glutamatergic neurotransmission by removal of extracellular Glu via energy-dependent Glu transporters (39), because the $V_{\mathrm{NT}}$ of $0.17 \mu \mathrm{mol} \cdot \mathrm{g}^{-1}$. $\min ^{-1}$ (Table 2) requires $\sim 0.35 \mu \mathrm{mol} \cdot \mathrm{g}^{-1} \cdot \mathrm{min}^{-1}$ of ATP for glutamine synthetase and the Na-K pump. An important consequence of the measured energetics is that it underlines the importance of coupled glial energy metabolism to that in neurons, as previously pointed out by Magistretti et al. (39). However, it also stresses the importance of oxidative metabolism, in that even minor fluxes in oxidative glucose combustion can easily produce more ATP than the much larger flux through glycolysis, even in glia (18).

In neurons, if glial lactate is assumed to be the major energy source, the rate of neuronal ATP generation (i.e., $30 \times V_{\mathrm{PDH}}$ ) is $17 \mu \mathrm{mol} \cdot \mathrm{g}^{-1} \cdot \mathrm{min}^{-1}$, suggesting that, although glial oxygen consumption is significant, it is a minor component of total brain oxygen consumption, contributing one-fifth to one-seventh of the oxygen consumption measured by ${ }^{13} \mathrm{C}$ MRS. 
Table 5. Sensitivity of $V_{N T}, C M R_{G l c(o x)}, V_{G}, V_{P D H}$, and $V_{P C}$ on the assumed cellular distribution of glutamate

\begin{tabular}{|c|c|c|c|c|c|}
\hline$\alpha^{*}$ & $V_{\mathrm{PDH}}$ & $\mathrm{CMR}_{\mathrm{Glc}(\mathrm{ox})}$ & $V_{\mathrm{NT}}$ & $V_{\mathrm{PC}}$ & $V_{\mathrm{g}}$ \\
\hline 0.033 & $0.60 \pm 0.06$ & $0.41 \pm 0.03$ & $0.25 \pm 0.07$ & $0.09 \pm 0.02$ & $0.03 \pm 0.04$ \\
\hline 0.1 & $0.58 \pm 0.06$ & $0.41 \pm 0.03$ & $0.20 \pm 0.06$ & $0.09 \pm 0.02$ & $0.05 \pm 0.04$ \\
\hline 0.2 & $0.54 \pm 0.06$ & $0.41 \pm 0.03$ & $0.14 \pm 0.04$ & $0.09 \pm 0.02$ & $0.08 \pm 0.04$ \\
\hline 0.3 & $0.48 \pm 0.06$ & $0.40 \pm 0.03$ & $0.09 \pm 0.04$ & $0.10 \pm 0.02$ & $0.13 \pm 0.05$ \\
\hline 0.5 & $0.37 \pm 0.06$ & $0.41 \pm 0.03$ & $0.05 \pm 0.04$ & $0.11 \pm 0.02$ & $0.22 \pm 0.06$ \\
\hline
\end{tabular}

Fluxes are expressed in $\mu \mathrm{mol} \cdot \mathrm{g}^{-1} \cdot \mathrm{min}^{-1}$ and shown as means $\pm \mathrm{SE} .{ }^{*} \mathrm{Glu}^{(\mathrm{g})}=\alpha \mathrm{Glu}_{\mathrm{tot}}, \mathrm{Glu}^{(\mathrm{n})}=(1-\alpha) \mathrm{Glu}_{\text {tot }}$, where $\mathrm{Glu}_{\mathrm{tot}}=\mathrm{Glu}^{(\mathrm{g})}+$ $\mathrm{Glu}^{(\mathrm{n})}$.

Ideally, it is desirable to have a sufficiently large metabolic pool directly associated with the metabolic reactions, as is the case, e.g., for lactate in tumors (69). In the case of the TCA cycle, however, it appears that mitochondrial TCA cycle intermediates are below detectability in vivo. This requires the detection of isotope kinetics via the amino acids, which are in exchange with the TCA cycle intermediates. Of critical importance in this regard is the delay by which the isotope labeling kinetics of the (cytosolic) amino acid lag behind those of the associated (mitochondrial) TCA intermediate. Consider, for instance, the two pairs OAA/Asp and OG/Glu: it is clear that the rate of exchange $V_{\mathrm{x}}$ relative to the pool size dictates to what extent the isotope kinetics in the amino acid reflect those of the associated intermediate. Hence, for a given $V_{\mathrm{x}}$, Asp kinetics approximate those of OAA approximately four times faster than the kinetics of Glu mimic those of OG (Fig. 3B) because of the approximately fourfold lower Asp pool size.

Previous studies have focused on the question of whether the rate of label exchange between cytosolic Glu and mitochondrial OG is fast compared with the TCA cycle rate, $V_{\mathrm{PDH}}(44,45,66,76)$. In the heart, this ratio was shown to vary and to be closer to $1(66,76)$. This appears also to be the case in skeletal muscle (30). In contrast, a report in brain estimated $V_{\mathrm{x}}$ at 57 $\mu \mathrm{mol} \cdot \mathrm{g}^{-1} \cdot \min ^{-1}(44,45)$. Such a high rate of exchange of negatively charged OG or Glu represents a rather high rate of exchange of ions that must occur in the presence of the electrochemical gradient.

Our exchange rates are clearly lower than those reported in Refs. 44 and 45, which were based on early studies performed in the late 1980s and early 1990s. For example, the measurements were performed in large volumes encompassing a significant fraction of the brain. Because of the complexity of the modeling and scarcity of experimental detail in these early studies and differences in modeling, it is difficult to pinpoint exactly the reason why our results are much lower. The early modeling studies in brain apparently did not involve simultaneous fitting of all measured time courses, as judged from the absence of a covariance matrix or discussion thereof, and from the absence of a described total cost function. Furthermore, the sensitivity of the TCA cycle flux on the precise value of $V_{\mathrm{x}}$ has not been reported in brain. As pointed out by others (76), the assessment of $V_{\mathrm{x}}$ from Glu results in a large covariance between $V_{\mathrm{PDH}}$ and $V_{\mathrm{x}}$, and this covariance may have contributed to some numerical inaccuracy. In contrast, our simulations shown in Table 1 suggest that the measurement of Asp-labeling kinetics alone can greatly reduce the influence of $V_{\mathrm{x}}$ on the measured TCA cycle rate. Therefore, the measurement of Asp kinetics allows in the fitting process a rather robust measurement of the TCA cycle rate, which (once known) allows a more precise measurement of $V_{\mathrm{x}}$. A similar approach has been applied in the heart, where oxygen consumption measurements were combined with Glu turnover to achieve excellent quantification of $V_{\mathrm{x}}$ by elimination of the large numerical covariance (76), whereas in Refs. 44 and 45, the reported errors in $V_{\mathrm{x}}$ are high.

The exchange between OG and Glu on one hand and between Asp and OAA on the other hand is also an integral component of the malate-aspartate shuttle, which transports the two NADH produced by oxidative glycolysis into the mitochondrion to maintain the cytosolic redox potential (Fig. $3 B$ ). Therefore $V_{\mathrm{x}}$ cannot be smaller than $V_{\mathrm{PDH}}$, inasmuch as the glycerol phosphate shuttle plays a quantitatively minor role in maintaining the cytosolic redox potential in brain. Therefore, the TCA cycle rate was assumed to provide a lower limit for the exchange rate $V_{\mathrm{x}}$ (Fig. $1 B$ ). We also used the fact that isotope kinetics in a detected amino acid mimic the isotope kinetics in the corresponding TCA cycle intermediate much better if the pool size is reduced, as illustrated in Fig. 3A. Therefore, we also incorporated Asp labeling in our analysis, in addition to Glu and Gln. The resulting exchange rate had a skewed error distribution to higher values but was statistically not different from the theoretical mini-

Table 6. Sensitivity of $V_{P D H}, V_{N T}, C M R_{G l c(o x)}, V_{G}$, and $V_{P C}$ to the assumed cellular distribution of glutamine

\begin{tabular}{|c|c|c|c|c|c|}
\hline$\beta^{*}$ & $V_{\mathrm{PDH}}$ & $\mathrm{CMR}_{\text {Gle(ox) }}$ & $V_{\mathrm{NT}}$ & $V_{\mathrm{PC}}$ & $V_{\mathrm{g}}$ \\
\hline 0.033 & $0.61 \pm 0.07$ & $0.43 \pm 0.04$ & $0.25 \pm 0.07$ & $0.099 \pm 0.02$ & $0.05 \pm 0.05$ \\
\hline 0.25 & $0.62 \pm 0.07$ & $0.43 \pm 0.04$ & $0.25 \pm 0.07$ & $0.099 \pm 0.02$ & $0.04 \pm 0.05$ \\
\hline 0.5 & $0.63 \pm 0.07$ & $0.44 \pm 0.05$ & $0.25 \pm 0.07$ & $0.100 \pm 0.02$ & $0.05 \pm 0.05$ \\
\hline
\end{tabular}

Values are means $\pm \mathrm{SE}$ expressed in $\mu \mathrm{mol} \cdot \mathrm{g}^{-1} \cdot \mathrm{min}^{-1}$. ${ }^{*} \mathrm{Gln}^{(\mathrm{n})}=\beta \mathrm{Gln}_{\text {tot }}, \mathrm{Gln}^{(\mathrm{g})}=\mathrm{Gln}^{(\mathrm{n})}$. 
mum afforded by $V_{\mathrm{PDH}}$. A low rate of exchange between OG and Glu on the order of the flux through pyruvate dehydrogenase implies that the malate-aspartate shuttle is a substantial mechanism by which label is exchanged between the cytosolic amino acids Glu and Asp and their metabolic partners in the TCA cycle. This points to the potential that the rate of exchange between Glu and OG can change under widely varying metabolic conditions and thus cannot a priori be assumed to be at a constant high level.

Recently, it has been postulated that the rate of glutamatergic action, assumed to correspond to the rate of neuronal Glu uptake into glia and interconversion to Gln (also termed the glutamate-glutamine "cycle") is stoichiometrically related to the oxidative glucose consumption, $\mathrm{CMR}_{\mathrm{Glc}(\mathrm{ox})}$. In our study, this ratio was found to be substantially lower than the $1: 1$ ratio reported in rat brain $(57,67)$. The differences can potentially be ascribed to two assumptions in that study, namely that turnover of Glu $\mathrm{C} 4$ was assumed to represent total $\mathrm{CMR}_{\mathrm{Glc}(\mathrm{ox})}$ and turnover of Gln $\mathrm{C} 4$ was assumed to represent exclusively the glutamate-glutamine "cycle." Indeed, in our study we find that when the flux through glutamine synthetase, $V_{\text {syn }}$, was correlated with the oxidative glucose consumption, $\mathrm{CMR}_{\mathrm{Glc}(\mathrm{ox})}$, a ratio of $0.8 \pm 0.2$ was calculated that is much closer to the reported relative rates. However, the contribution of pyruvate carboxylase needs to be subtracted from the flux through glutamine synthetase, resulting in a substantial reduction of this ratio. In this calculation, it should be noted that nonoxidative contributions to the overall flux through hexokinase, glycogen metabolism (13), as well as metabolism of GABAergic neurons, have not been taken into account, which would lead to an even larger discrepancy between the ATP produced by the glial compartment and the ATP required for the Glu-Gln cycle. Furthermore, it has been shown that astrocytes can increase their oxygen consumption after glutamate uptake (18). Nevertheless, it is quite possible that some form of monotonic relationship exists between energy metabolism and glutamatergic action, yet the precise relationship still remains to be fully characterized.

The presented results can depend on the assumed distribution of glutamate between the glial and neuronal compartments. For example, the assumed intercellular distribution of glutamate has a strong effect on the calculated rates (Table 5). The parameter that was systematically varied was $\alpha$, which was defined through the following relationships: $\mathrm{Glu}^{(\mathrm{g})}=\alpha \mathrm{Glu}_{\text {tot }}$, $\mathrm{Glu}^{(\mathrm{n})}=\left(1-\alpha \mathrm{Glu}_{\text {tot }}\right)$, where $\mathrm{Glu}_{\text {tot }}=\mathrm{Glu}^{(\mathrm{g})}+\mathrm{Glu}^{(\mathrm{n})}$. Likewise, the effect of changing the cellular distribution of glutamine was shown by varying the parameter $\beta$, defined by the relationships $\mathrm{Gln}^{(\mathrm{n})}=\beta \mathrm{Gln}_{\text {tot }}$, $\mathrm{Gln}^{(\mathrm{g})}=\left(1-\beta \mathrm{Gln}_{\mathrm{tot}}\right)$, where $\operatorname{Gln}_{\text {tot }}=\mathrm{Gln}^{(\mathrm{g})}+\mathrm{Gln}^{(\mathrm{n})}$, which was without effect on the modeling (Table 6). However, even the assumption that all but $3.3 \%$ of the metabolic glutamate pool is in neurons does not affect our suggestion that the relationship between glutamatergic action and glucose consumption is not stoichiometric, because this relationship increased only to $\sim 0.6$, oxidative generation of ATP in astrocytes decreased to $\sim 82 \%$, and glial relative to neuronal ATP generation was reduced to $\sim 10 \%$. Interestingly, in all simulations, the total oxidative glucose consumption remains a very stable measurement. The proposed modeling is subject to further refinement, but we think we have attempted the most complete modeling with the least number of assumptions to date. Our study, therefore, underlines the importance of making such assumptions in modeling complex biological data, and the recognition that previous models based on simpler data need to be considered with appropriate caution.

We conclude that pyruvate carboxylation may be a significant contributor to the flux though glutamine synthetase in the human brain in vivo. Glutamatergic action contributes to the flux through glutamine synthetase, but we conclude that, at rest, oxidative glucose consumption is not necessarily 1:1 stoichiometrically correlated with glutamatergic action. Finally, we conclude that the exchange of label between 2-oxoglutarate and glutamate may be affected by the cellular energy status.

This study was supported by National Institutes of Health Grants RR-08079 (K. Ugurbil) from the Biotechnology Resource Program and RR-00400 from the Clinical Research Center program of the National Center for Regional Resources, R01-NS-35192 (E. R. Seaquist), R01-NS-38672 (R. Gruetter), and a grant from the Whitaker Foundation (R. Gruetter).

\section{REFERENCES}

1. Adriany G and Gruetter R. A half volume coil for efficient proton decoupling in humans at 4 Tesla. J Magn Reson 125: 178-184, 1997.

2. Arriza JL, Fairman WA, Wadiche JI, Murdoch GH, Kavanaugh MP, and Amara SG. Functional comparisons of three glutamate transporter subtypes cloned from human motor cortex. J Neurosci 14: 5559-5569, 1994.

3. Bachelard H. Landmarks in the application of 13C-magnetic resonance spectroscopy to studies of neuronal/glial relationships. Dev Neurosci 20: 277-288, 1998.

4. Bachelard H and Badar-Goffer R. NMR spectroscopy in neurochemistry. J Neurochem 61: 412-429, 1993.

5. Beckmann N, Turkalj I, Seelig J, and Keller U. 13C NMR for the assessment of human brain glucose metabolism in vivo. Biochemistry 30: 6362-6366, 1991.

6. Bergles DE, Dzubay JA, and Jahr CE. Glutamate transporter currents in bergmann glial cells follow the time course of extrasynaptic glutamate. Proc Natl Acad Sci USA 94: 1482114825, 1997.

7. Berl S, Nicklas WJ, and Clarke DD. Compartmentation of citric acid cycle metabolism in brain: labelling of glutamate, glutamine, aspartate and gaba by several radioactive tracer metabolites. J Neurochem 17: 1009-1015, 1970.

8. Bier DM, Arnold KJ, Sherman WR, Holland WH, Holmes WF, and Kipnis DM. In-vivo measurement of glucose and alanine metabolism with stable isotopic tracers. Diabetes 26: 1005-1015, 1977.

9. Brand A, Richter-Landsberg C, and Leibfritz D. Multinuclear NMR studies on the energy metabolism of glial and neuronal cells. Dev Neurosci 15: 289-298, 1993.

10. Chance EM, Seeholzer SH, Kobayashi K, and Williamson JR. Mathematical analysis of isotope labeling in the citric acid cycle with applications to 13C NMR studies in perfused rat hearts. J Biol Chem 258: 13785-13794, 1983.

11. Cheeseman AJ and Clark JB. Influence of the malate-aspartate shuttle on oxidative metabolism in synaptosomes. $J$ Neurochem 50: 1559-1565, 1988. 
12. Choi I, Lee S, Kim S, and Gruetter R. In vivo measurements of brain glucose transport using the reversible Michaelis-Menten model and simultaneous measurements of cerebral blood flow changes during hypoglycemia. J Cereb Blood Flow Metab. In press.

13. Choi IY, Tkac I, Ugurbil K, and Gruetter R. Noninvasive measurements of [1-(13)C]glycogen concentrations and metabolism in rat brain in vivo. J Neurochem 73: 1300-1308, 1999.

14. Cohen DM and Bergman RN. SYNTAX: a rule-based stochastic simulation of the time-varying concentrations of positional isotopomers of metabolic intermediates. Comput Biomed Res 27: 130-147, 1994.

15. Cooper A and Plum F. Biochemistry and physiology of brain ammonia. Physiol Rev 67: 440-519, 1987.

16. Cooper AJ and Lai JC. Cerebral ammonia metabolism in normal and hyperammonemic rats. Neurochem Pathol 6: 67-95, 1987.

17. Cruz F and Cerdan S. Quantitative 13C NMR studies of metabolic compartmentation in the adult mammalian brain. NMR Biomed 12: 451-462, 1999.

18. Eriksson G, Peterson A, Iverfeldt K, and Walum E. Sodiumdependent glutamate uptake as an activator of oxidative metabolism in primary astrocyte cultures from newborn rat. Glia 15: 152-156, 1995.

19. Gruetter R. Automatic, localized in vivo adjustment of all firstand second-order shim coils. Magn Reson Med 29: 804-811, 1993.

20. Gruetter R, Adriany G, Merkle H, and Andersen PM. Broadband decoupled, $1 \mathrm{H}$ localized 13C MRS of the human brain at 4 Tesla. Magn Reson Med 36: 659-664, 1996.

21. Gruetter R, Novotny EJ, Boulware SD, Mason GF, Rothman DL, Prichard JW, and Shulman RG. Localized 13C NMR spectroscopy of amino acid labeling from [1-13C] D-glucose in the human brain. J Neurochem 63: 1377-1385, 1994.

22. Gruetter R, Novotny EJ, Boulware SD, Rothman DL, Mason GF, Shulman GI, Shulman RG, and Tamborlane WV. Direct measurement of brain glucose concentrations in humans by 13C NMR spectroscopy. Proc Natl Acad Sci USA 89: 11091112,1992

23. Gruetter R, Seaquist E, Kim S-W, and Ugurbil K. Localized in vivo ${ }^{13} \mathrm{C}$ NMR of glutamate metabolism. Initial results at 4 Tesla. Dev Neurosci 20: 380-388, 1998.

24. Gruetter R, Ugurbil K, and Seaquist ER. Steady-state cerebral glucose concentrations and transport in the human brain. J Neurochem 70: 397-408, 1998.

25. Gundersen V, Chaudhry FA, Bjaalie JG, Fonnum F, Ottersen OP, and Storm-Mathisen J. Synaptic vesicular localization and exocytosis of L-aspartate in excitatory nerve terminals: a quantitative immunogold analysis in rat hippocampus. J Neurosci 18: 6059-6070, 1998.

26. Hassel B, Bachelard H, Jones P, Fonnum F, and Sonnewald U. Trafficking of amino acids between neurons and glia in vivo. Effects of inhibition of glial metabolism by fluoroacetate. J Cereb Blood Flow Metab 17: 1230-1238, 1997.

27. Hetherington HP, Pan JW, Mason GF, Adams D, Vaughn MJ, Twieg DB, and Pohost GM. Quantitative H-1 spectroscopic imaging of human brain at $4.1 \mathrm{~T}$ using image segmentation. Magn Reson Med 36: 21-29, 1996.

28. Hogstad S, Svenneby G, Torgner IA, Kvamme E, Hertz L, and Schousboe A. Glutaminase in neurons and astrocytes cultured from mouse brain: kinetic properties and effects of phosphate, glutamate, and ammonia. Neurochem Res 13: 383$388,1988$.

29. Hyder F, Rothman DL, Mason GF, Rangarajan A, Behar KL, and Shulman RG. Oxidative glucose metabolism in rat brain during single forepaw stimulation: a spatially localized $1 \mathrm{H}[13 \mathrm{C}]$ nuclear magnetic resonance study. J Cereb Blood Flow Metab 17: 1040-1047, 1997.

30. Jucker BM, Rennings AJ, Cline GW, Petersen KF, and Shulman GI. In vivo NMR investigation of intramuscular glucose metabolism in conscious rats. Am J Physiol Endocrinol Metab 273: E139-E148, 1997.

31. Katz J, Lee WN, Wals PA, and Bergner EA. Studies of glycogen synthesis and the Krebs cycle by mass isotopomer analysis with [U-13C]glucose in rats. J Biol Chem 264: 1299413004, 1989.

32. Knudsen G, Paulson O, and Hertz M. Kinetic analysis of the human blood-brain barrier transport of lactate and its influence by hypercapnia. J Cereb Blood Flow Metab 11: 581-586, 1991.

33. Kunnecke B, Cerdan S, and Seelig J. Cerebral metabolism of [1,2-13C2]glucose and [U-13C4]3-hydroxybutyrate in rat brain as detected by 13C NMR spectroscopy. NMR Biomed 6: 264-277, 1993.

34. Laake J, Slyngstad T, Haug F, and Ottersen O. Glutamine from glial cells is essential for the maintenance of the nerve terminal pool of glutamate: immunogold evidence from hippocampal slice cultures. J Neurochem 65: 871-881, 1995.

35. Laine RA and Sweeley CC. Analysis of trimethylsilyl Omethyloximes of carbohydrates by combined gas-liquid chromatography-mass spectrometry. Anal Biochem 43: 533-538, 1971.

36. LaNoue KF and Tischler ME. Electrogenic characteristics of the mitochondrial glutamate-aspartate antiporter. J Biol Chem 249: 7522-7528, 1974.

37. Lapidot A and Gopher A. Cerebral metabolic compertmentation. Estimation of glucose flux via pyruvate carboxylase/pyruvate dehydrogenase by $13 \mathrm{C}$ NMR isotopomer analysis of [U-13C] D-glucose metabolites. J Biol Chem 269: 27198-27208, 1994.

38. Leo GC, Driscoll BF, Shank RP, and Kaufman E. Analysis of [1-13C]D-glucose metabolism in cultured astrocytes and neurons using nuclear magnetic resonance spectroscopy. Dev Neurosci 15: 282-288, 1993.

39. Magistretti PJ, Sorg O, Yu N, Martin JL, and Pellerin L. Neurotransmitters regulate energy metabolism in astrocytes: implications for the metabolic trafficking between neural cells. Dev Neurosci 15: 306-312, 1993.

40. Malloy C, Sherry A, and Jeffrey F. Analysis of tricarboxylic acid cycle of the heart using ${ }^{13} \mathrm{C}$ isotope isomers. Am J Physiol Heart Circ Physiol 259: H987-H995, 1990.

41. Martin M, Portais JC, Labouesse J, Canioni P, and Merle M. [1-13C]glucose metabolism in rat cerebellar granule cells and astrocytes in primary culture. Evaluation of flux parameters by 13C- and 1H-NMR spectroscopy. Eur J Biochem 217: 617625, 1993.

42. Martinez-Hernandez A, Bell KP, and Norenberg MD. Glutamine synthetase: glial localization in brain. Science 195: 13561358, 1976.

43. Mason GF, Behar KL, Rothman DL, and Shulman RG. NMR determination of intracerebral glucose concentration and transport kinetics in rat brain. J Cereb Blood Flow Metab 12: 448-455, 1992.

44. Mason GF, Gruetter R, Rothman DL, Behar KL, Shulman RG, and Novotny EJ. Simultaneous determination of the rates of the TCA cycle, glucose utilization, $\alpha$-ketoglutarate/glutamate exchange, and glutamine sysnthesis in human brain by NMR. J Cereb Blood Flow Metab 15: 12-25, 1995.

45. Mason GF, Rothman DL, Behar KL, and Shulman RG. NMR determination of the TCA cycle rate and alpha- ketoglutarate/glutamate exchange rate in rat brain. J Cereb Blood Flow Metab 12: 434-447, 1992.

46. McKenna M, Sonnewald U, Huang X, Stevenson J, and Zielke H. Exogenous glutamate concentration regulates the metabolic fate of glutamate in astrocytes. J Neurochem 66: 386-393, 1996

47. McKenna MC, Tildon JT, Stevenson JH, and Hopkins IB. Energy metabolism in cortical synaptic terminals from weanling and mature rat brain: evidence for multiple compartments of tricarboxylic acid cycle activity. Dev Neurosci 16: 291-300, 1994.

48. Mennerick S and Zorumski C. Glial contributions to excitatory neurotransmission in cultured hippocampal cells. Nature 368: 59-62, 1994.

49. Mescher M, Merkle H, Kirsch J, Garwood M, and Gruetter R. Simultaneous water suppression and editing in vivo. NMR Biomed 11: 266-272, 1998.

50. Morgan CR and Lazarow A. Immunoassay of insulin: two antibody system. Diabetes 12: 115-126, 1963.

51. Ottersen O, Zhang N, and Walberg F. Metabolic compartmentation of glutamate and glutamine: morphological evidence 
obtained by quantitative immunocytochemistry in rat cerebellum. Neuroscience 46: 519-534, 1992.

52. Patel AJ, Hunt A, Gordon RD, and Balazs R. The activities in different neural cell types of certain enzymes associated with the metabolic compartmentation glutamate. Brain Res 256: 3-11, 1982.

53. Petroff OA, Pleban LA, and Spencer DD. Symbiosis between in vivo and in vitro NMR spectroscopy: the creatine, $\mathrm{N}$-acetylaspartate, glutamate, and GABA content of the epileptic human brain. Magn Reson Imag 13: 1197-1211, 1995.

54. Petroff OA, Spencer DD, Alger JR, and Prichard JW. High-field proton magnetic resonance spectroscopy of human cerebrum obtained during surgery for epilepsy. Neurology 39: 1197-1202, 1989

55. Pfeuffer J, Tkac I, and Gruetter R. Extracellular-intracellular distribution of glucose and lactate in the rat brain assessed noninvasively by diffusion-weighted $1 \mathrm{H}$ nuclear magnetic resonance spectroscopy in vivo. J Cereb Blood Flow Metab 20: 736$746,2000$.

56. Rothman DL, Novotny EJ, Shulman GI, Howseman AM, Petroff OAC, Mason GF, Nixon T, Hanstock CC, Prichard JW, and Shulman RG. 1H-[13C] NMR measurement of [4-13C] glutamate. Proc Natl Acad Sci USA 89: 9603-9306, 1992.

57. Rothman DL, Sibson NR, Hyder F, Shen J, Behar KL, and Shulman RG. In vivo nuclear magnetic resonance spectroscopy studies of the relationship between the glutamate-glutamine neurotransmitter cycle and functional neuroenergetics. Philos Trans R Soc Lond B Biol Sci 354: 1165-1177, 1999.

58. Schuldiner S, Shirvan A, and Linial M. Vesicular neurotransmitter transporters: from bacteria to humans. Physiol Rev 75: 369-392, 1995.

59. Seaquist E, Tkac I, and Gruetter R. Glucose transport kinetics in cerebral gray and white matter during physiologic insulinemia. Diabetes 49: 1263-1263, 2000.

60. Seaquist ER. Comparison of arterialized venous sampling from the hand and the foot in the assessment of in vivo glucose metabolism. Metabolism 46: 1364-1366, 1997.

61. Seaquist ER, Pyzdrowski K, Moran A, Teuscher AU, and Robertson RP. Insulin-mediated and glucose-mediated glucose uptake following hemipancreatectomy in healthy human donors. Diabetologia 37: 1036-1043, 1994.

62. Shank R and Aprison M. Biochemical aspects of the neurotransmitter function of glutamate. In: Glutamic Acid: Advances in Biochemistry and Physiology. New York: Raven, 1979, p. 139-150.

63. Shank RP, Bennett GS, Freytag SO, and Campbell GL. Pyruvate carboxylase: an astrocyte-specific enzyme implicated in the replenishment of amino acid neurotransmitter pools. Brain Res 329: 364-367, 1985.

64. Shank RP, Leo GC, and Zielke HR. Cerebral metabolic compartmentation as revealed by nuclear magnetic resonance anal- ysis of D-[1-13C]glucose metabolism. J Neurochem 61: 315-323, 1993.

65. Shen J, Petersen KF, Behar KL, Brown P, Nixon TW, Mason GF, Petroff OA, Shulman GI, Shulman RG, and Rothman DL. Determination of the rate of the glutamate/ glutamine cycle in the human brain by in vivo 13C NMR. Proc Natl Acad Sci USA 96: 8235-8240, 1999.

66. Sherry AD, Zhao P, Wiethoff AJ, Jeffrey FM, and Malloy CR. Effects of aminooxyacetate on glutamate compartmentation and TCA cycle kinetics in rat hearts. Am J Physiol Heart Circ Physiol 274: H591-H599, 1998.

67. Sibson NR, Dhankhar A, Mason GF, Rothman DL, Behar KL, and Shulman RG. Stoichiometric coupling of brain glucose metabolism and glutamatergic neuronal activity. Proc Natl Acad Sci USA 95: 316-321, 1998

68. Sonnewald U, Gribbestad IS, Westergaard N, Nilsen G, Unsgard G, Schousboe A, and Petersen SB. Nuclear magnetic resonance spectroscopy: biochemical evaluation of brain function in vivo and in vitro. Neurotoxicology 15: 579-590, 1994.

69. Terpstra M, Gruetter R, High WB, Mescher M, DelaBarre L, Merkle H, and Garwood M. Lactate turnover in rat glioma measured by in vivo nuclear magnetic resonance spectroscopy. Cancer Res 58: 5083-5088, 1998.

70. Tyler JL, Strother SC, Zatorre RJ, Alivisatos B, Worsley KJ, Diksic M, and Yamamoto YL. Stability of regional cerebral glucose metabolism in the normal brain measured by positron emission tomography. J Nucl Med 29: 631-642, 1988.

71. Van den Berg C. A model of compartmentation in mouse brain based on glucose and acetate metabolism. In: Metabolic Compartmentation in the Brain, edited by E Balazs and J Cremer. London: MacMillan, 1973, p. 137-166.

72. Van Zijl PC, Davis D, Eleff SM, Moonen CT, Parker RJ, and Strong JM. Determination of cerebral glucose transport and metabolic kinetics by dynamic MR spectroscopy. Am J Physiol Endocrinol Metab 273: E1216-E1227, 1997.

73. Wang $\mathbf{Y}$ and Floor E. Dynamic storage of glutamate in rat brain synaptic vesicles. Neurosci Lett 180: 175-178, 1994.

74. Waniewski RA and Martin DL. Preferential utilization of acetate by astrocytes is attributable to transport. $J$ Neurosci 18 : 5225-5233, 1998.

75. Wurdig S and Kugler P. Histochemistry of glutamate metabolizing enzymes in the rat cerebellar cortex. Neurosci Lett 130: $165-168,1991$.

76. Yu X, Alpert NM, and Lewandowski ED. Modeling enrichment kinetics from dynamic ${ }^{13} \mathrm{C}$ NMR spectra: theoretical analysis and practical considerations. Am J Physiol Cell Physiol 272: C2037-C2048, 1997.

77. Yudkoff M, Nissim I, Daikhin Y, Lin Z, Nelson D, Pleasure D, and Erecinska M. Brain glutamate metabolism: neuronalastroglial relationships. Dev Neurosci 15: 343-350, 1993.

78. Zigmond MJ. Fundamental Neuroscience. San Diego, CA: Academic, 1999, p. 402-412. 